\title{
Chinlechelys from the Upper Triassic of New Mexico, USA, and the origin of turtles
}

\author{
Asher J. Lichtig and Spencer G. Lucas
}

\begin{abstract}
Chinlechelys tenertesta is a turtle from the Upper Triassic Bull Canyon Formation of the Chinle Group of eastern New Mexico, USA, which has largely been ignored in recent studies of the phylogenetic position of turtles (Testudinata) within the Tetrapoda. Here, we present the first comprehensive description of the morphology of Chinlechelys tenertesta and reaffirm its unequivocal support for the composite model of costal bone formation in turtles. We also document the presence in Chinlechelys tenertesta of separate ribs reminiscent of those of Odontochelys semitestacea, a Late Triassic prototurtle from China, and costal plates, as would be expected under the composite model. This indicates that the two-phase embryological model of costal and plastral bone formation approximately corresponds to the formation of the endochondal rib and plastral primary ossifications and then the later dermal formation of the plastral and costal plates, as is suggested by the composite model. We challenge the identification of Permian Eunotosaurus africanus as a stem turtle and instead suggest that it is a caseid synapsid. We do not consider Pappochelys rosinae to be a close relative of turtles. It more closely resembles the basal placodont sauropterygians, particularly Palatodonta bleekeri. Indeed, phylogenetic analysis based on correctly coded character states places Pappochelys rosinae in the Sauropterygia as the sister taxon of placodonts. The morphology of Chinlechelys tenertesta supports the placement of Testudines outside of crown Sauria, as a taxon derived from pareiasaurs based on the morphology of the dorsal osteoderms and skull roof.
\end{abstract}

Asher J. Lichtig. New Mexico Museum of Natural History \& Science, 1801 Mountain Road N. W., Albuquerque, New Mexico 87104, USA. ajlichtig@gmail.com

Spencer G. Lucas. New Mexico Museum of Natural History \& Science, 1801 Mountain Road N. W., Albuquerque, New Mexico 87104, USA. spencer.lucas@state.nm.us

Keywords: Chinlechelys; Triassic; turtle; pareiasaur; Odontochelys; Proganochelys

Submission: 10 May 2018. Acceptance: 9 March 2021.

Lichtig, Asher J. and Lucas, Spencer G. 2021. Chinlechelys from the Upper Triassic of New Mexico, USA, and the origin of turtles. Palaeontologia Electronica, 24(1):a13. https://doi.org/10.26879/886

palaeo-electronica.org/content/2021/3316-triassic-turtle-chinlechelys

Copyright: April 2021 Paleontological Society.

This is an open access article distributed under the terms of Attribution-NonCommercial-ShareAlike 4.0 International (CC BY-NC-SA 4.0 ), which permits users to copy and redistribute the material in any medium or format, provided it is not used for commercial purposes and the original author and source are credited, with indications if any changes are made.

creativecommons.org/licenses/by-nc-sa/4.0/ 


\section{INTRODUCTION}

The origin of turtles (Testudinata sensu Joyce et al., 2004) has been a persistent and much discussed problem in vertebrate paleontology. Turtles are unique among vertebrates in their location of the shoulder girdle within the rib cage (Burke, 1989; Lyson et al., 2012; Lyson et al., 2014). Furthermore, the fusion of this rib cage and possibly the gastralia into an immovable box (carapace and plastron) in most turtles including the most basal species is unique among amniotes. These unique changes and others scattered throughout the skeleton have hampered attempts to identify the closest relatives of turtles. Many amniote taxa have morphology that appears to share possible synapomorphies with turtles, but nothing unquestionably links them to turtles.

Since the late 1800 s, many hypotheses of turtle relationships have been proposed, but none have endured the test of time (e.g., Cope 1871; Watson, 1914). This has been exacerbated by the rarity of early turtle fossils. More perplexing is the lack of study that many of the earliest turtles have received. Most are given a brief description and either a name or a reference to a known taxon, but nothing else. A case in point is Chinlechelys tenertesta, which challenges many ideas of turtle shell formation, both old and new.

Chinlechelys tenertesta is a turtle from the Late Triassic (Norian) of New Mexico that has received modest attention to date (Lucas et al., 2000; Joyce et al., 2009). This turtle adds to the discussion of turtle origins, particularly the origin of costal bones. Here, we provide new information on the morphology of Chinlechelys tenertesta and analyze its impact on the long running discussion of turtle origins.

\section{SOME HISTORY}

Turtles have been hypothesized to be the sister group to nearly every major amniote taxon, including: procolophonids, pareiasaurs, captorhinomorphs, synapsids, saurians, archosaurs, sauropterygians, lepidosaurs, and a variety of subgroups within these groups (Carroll, 2013; Figure 1). Those conclusions have been based on adult skeletal morphology, molecular phylogenetics, soft tissue morphology, histology, and ontogenetic staging. This has led to various arguments about the validity of different methods of phylogenetic analysis or their potential biases, ranging from issues arising from long branch attraction to morphological convergence. Most of these prob- lems stem from the fact that turtles are so different from other tetrapods that they challenge many of the commonly used methods of hypothesizing phylogenetic relationships. The lack of convincing sister-group or stem turtle (e.g., stem-testudine) body fossils prior to the Late Triassic (Carnian) has also helped to confound any attempt at a conclusive answer from the fossil record.

The history of arguments over the origin of the turtle shell and its impact on turtle origins were recently reviewed by several authors, including Carroll (2013), Rieppel (2013, 2017), Joyce (2015, 2017), and Szczygielski and Sulej (2019) obviating the need for a detailed review here. The hypotheses of turtle origins (Figure 1) have included descent from a diverse range of clades:

1. Cope (1871), Hay $(1905,1921)$ and other researchers in the late 1800 s and early 1900 s suggested an origin of turtles from the "Cotylosauria," which are now mostly classified as parareptiles (Tsuji and Müller, 2009). Though some are also classified as eureptiles and diadectomorphs (Laurin and Reisz, 1995). This is the classic anapsid origin of turtles.

2. Watson (1914) suggested that Eunotosaurus africanus, an enigmatic reptile from the middle Permian of South Africa, was the ancestral turtle (Figure 1.1). This hypothesis has been revived recently by Lyson et al. $(2010,2013 a$, b, 2016) and Bever et al. (2016).

3. Gardiner (1982) suggested that turtles have a sister group relationship with dicynodonts, but this idea has not been developed further (Figure 1.2).

4. Gauthier et al. (1988), in a cladistic analysis of the amniotes, suggested a sister group relationship of turtles with captorhinids (Figure 1.3) as previously suggested by Clark and Carroll (1973). Captorhinids were part of the "Cotylosauria" of Cope and others, so in some respects this was a return to the original hypothesis of Cope (1871).

5. Reisz and Laurin (1991) hypothesized a sister group relationship between the procolophonids and in particular Owenetta (Figure 1.4) and turtles. This hypothesis was further detailed in Laurin and Reisz (1995).

6. Lee (1997) suggested that turtles are the sister taxon to the Permian Pareiasauridae (Figure 1.5). This provided the first cladistic analysis of Gregory's (1946) hypothesis of turtle origins from the Pareiasauridae. 




FIGURE 1. Cladograms showing the various proposed placements of turtles (Testudines) relative to other amniotes. 1. Eunotosaurus as the ancestor of turtles (Watson, 1914). 2. Turtles as the sister group to the Dicynodontia Gardiner (1982). 3. Turtles as the sister group to the Captorhinidae (Gauthier et al., 1988). 4. Turtles as the sister group to Owenetta (Reisz and Laurin, 1991). 5. Turtles as the sister group to the Pareiasauridae (Lee, 1997). 6. Turtles as the sister group to the Sauropterygia (Rieppel and Reisz, 1999). 7. Turtles as a sister group to archosaurs (Hugal et al., 2007; Crawford et al., 2012; and Chiari et al., 2012).

7. Rieppel and Reisz (1999) argued for the diapsid origin of turtles as the sister taxon to the Sauropterygia (Figure 1.6).

8. Recent molecular studies have suggested that turtles are the sister taxon to archosaurs, including Hugall et al. (2007), Crawford et al. (2012), and Chiari et al. (2012); but see Lyson et al. (2012), Lu et al. (2013), and Joyce (2015) for a contrary viewpoint (Figure 1.7).

9. Data based on developmental timing (Werneburg and Sánchez -Villagra, 2009) indicate a placement of turtles outside crown Sauria (the most recent common ancestor of squamates and archosaurs), and this agrees with the suggestion that turtles were derived from parareptiles or, alternatively, captorhinomorphs.

Werneburg and Sánchez -Villagra's (2009) results are otherwise in almost complete agreement with recent molecular studies as to the phylogeny of turtles. This agrees with numbers 1, 4, 5, and 6 above.

Thus, a diverse range of taxa have been important to the discussion of turtle origins and come from a variety of localities and stratigraphic positions (Figures 2-3). The Permian taxa are concentrated in the Karoo Basin of South Africa. How- 

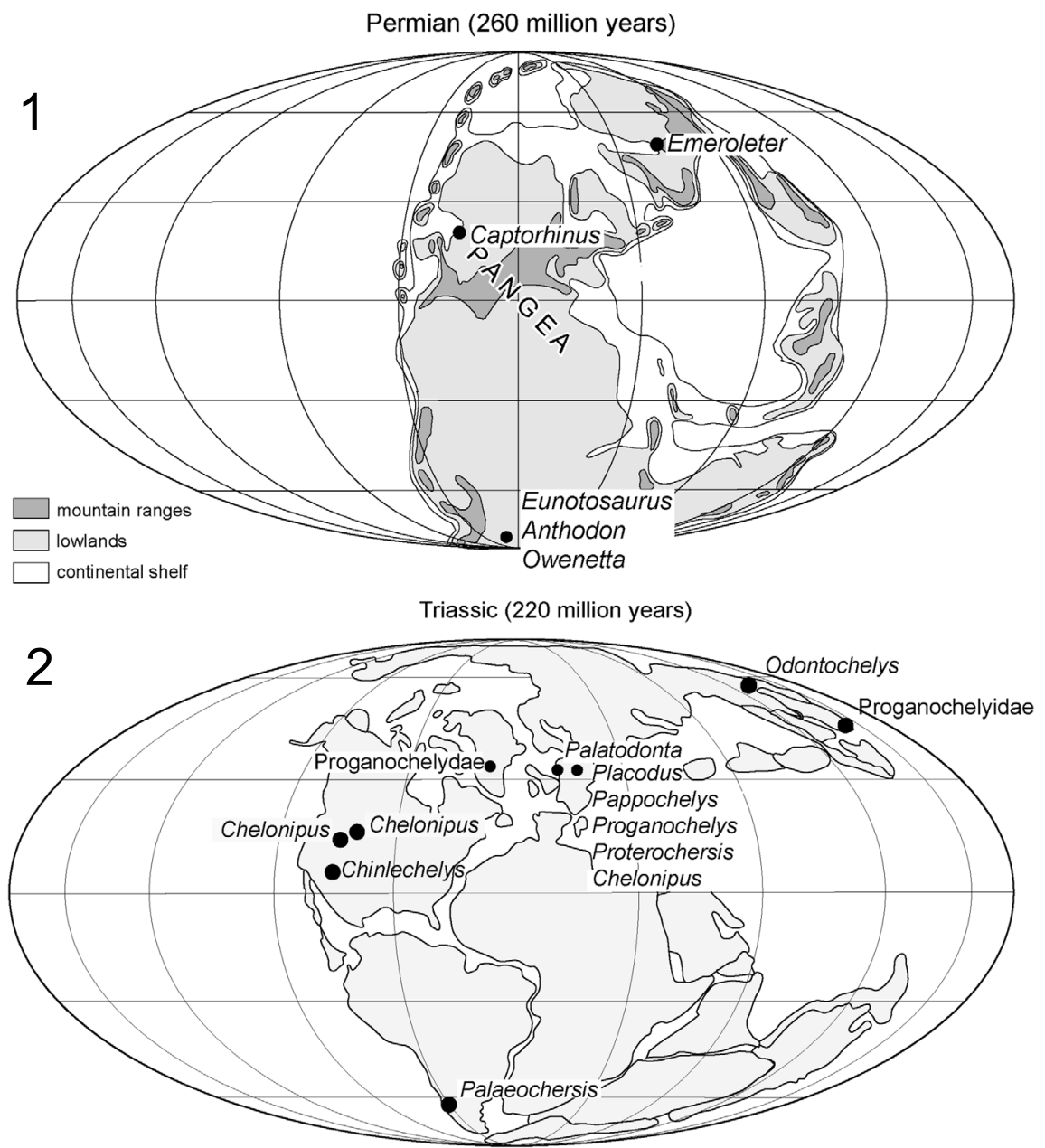

FIGURE 2. Paleogeographic location of genera of early turtles and other tetrapods discussed in this paper on maps of the Permian (1) and Triassic (2). Maps based on Wing and Sues (1992).

ever, two taxa, Emeroleter levis and Captorhinus, are known from Russia and the western United States, respectively (Figure 2.1). In contrast, the Triassic taxa are concentrated in Germany and the Netherlands (Figure 2.2). Importantly, the earliest known undisputed turtle body fossils are of Odontochelys semitestacea from the Carnian of China, with other basal turtles known from the Norian of New Mexico, Argentina, Thailand, Greenland, Germany, and Poland (Figures 2.2, 3) (Broin, 1984; Jenkins et al., 1994; Lucas et al., 2000; Sterli et al., 2007; Joyce et al., 2009; Sulej et al., 2012; Szczygielski and Sulej, 2016; Szczygielski, 2017; Szczygielski et al., 2018).

In recent years, the three hypotheses of turtle origins that have been explored in great detail posit sister group relationships of turtles to pareiasaurs, sauropterygians, or Eunotosaurus africanus. These hypotheses represent the current thinking on turtle origins, though all three of these hypotheses have been described as uncertain, with room for any of them to be correct, according to Lu et al. (2013) and Lee (2013).

Lee $(1993,1997)$ redescribed many of the Pareiasauridae and argued that the derived late Permian species Anthodon pricei is the sister taxon to turtles, suggesting the formation of costals via fusion of the ribs with the overlying osteoderms. This was challenged in part by Scheyer's (2007) studies of histology, suggesting that pareiasaur osteoderms and turtle carapace bones are formed in such a different manner that they cannot be considered homologous.

Rieppel and Reisz (1999) and others have argued for a diapsid origin of turtles, specifically allying them with the Triassic Sauropterygia. This group includes many previously suggested turtle ancestors, including the heavily armored placodont 


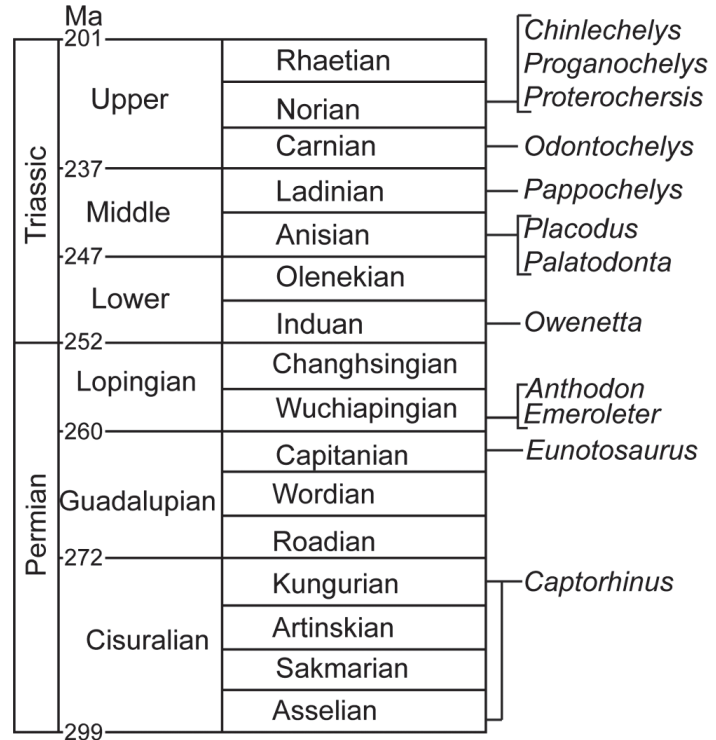

FIGURE 3. Temporal distribution of early turtles and other genera discussed in this paper.

Henodus. However, placodonts have in the past been argued to be a poor sister group for turtles, as their armor is formed in a manner different from that of turtles (Scheyer, 2007). Furthermore, the presence of Early Triassic turtle tracks suggests that turtles and their characteristic gait had evolved by late in the Early Triassic, which is as old or older than the oldest sauropterygian fossils (Rühle von Lilienstern, 1939; Haubold, 1971; Lovelace and Lovelace, 2012; Lichtig et al., 2018). This includes the low digital divarication, short internal trackway width-to-stride ratio, and the dual gait, well-known characteristic features of turtle tracks/trackways. Furthermore, the gait of turtles is quite different from the expected walking gait of sauropterygians based on their limited limb flexibility and longer bodies (Storrs, 1991). The length-to-width ratio of the trackways is inconsistent with those of a sauropterygian. This and other parts of sauropterygian anatomy lead us to suspect that their trackways would be more similar to those of extant lizards (Kubo, 2010) than to those of turtles.

The third hypothesis identifies the middle Permian synapsid Eunotosaurus africanus as a possible turtle ancestor as specifically proposed by Watson (1914) and later advocated as a sister group by Lyson et al. (2010, 2013a, b, 2016). Although first advocated about a century ago (Watson, 1914), this idea was largely abandoned until the 1980s, when the discovery of the first complete Eunotosaurus skulls gave it new credence. After this, Lee $(1993,1994)$ argued that Eunotosaurus is an aberrant caseid synapsid, a conclusion with which we generally agree (see below). However, this was questioned, starting with Lyson et al. (2010), who argued that Eunotosaurus is the sister taxon to turtles based on the rib configuration of Odontochelys semitestacea (Li et al., 2008).

The Eunotosaurus hypothesis was emphasized by subsequent articles that described the purported homologies of the skull, shell, and shoulder girdles of turtles (Lyson et al., 2013a, 2013b, 2016; Bever et al., 2015). While these followed the agreed upon concept that the turtle epiplastron and entoplastron were derived from the clavicles and interclavicles, they went a step further in suggesting that the nuchal bone derived from the cleithrum of a turtle ancestor. However, this is put into question by the presence of a cleithrum in the Jurassic turtle Kayentachelys aprix (Joyce et al., 2006), which rules out the homology of the nuchal bone and the cleithrum. This conflict is not effectively explained by Lyson et al. (2013a), who state that the sutures used to indicate the presence of a second bone, the cleithrum, are present in only one specimen of Kayentachelys. However, Joyce et al. (2006, figure 3) state that they are present in over half of the specimens of Kayentachelys and illustrate three of these, which show the suture as expected. Firsthand observations of a well-preserved complete entoplastron of Kayentachelys (Texas Memorial Museum 43687-109, Figure 4) confirm the presence of sutures (rather than fractures, as suggested by Lyson et al., 2013a) connecting the dorsal process identified as the cleithrum in Joyce et al. (2006). This conclusion is further supported by the presence of cleithra in the Middle Jurassic turtle Eileanchelys waldmani (Anquetin et al., 2008)

The hypothesis of the homology of the cleithrum and the nuchal bone of turtles was further suggested by Lyson et al. (2013a) to be supported by the placement of associated muscles in extant turtles. This was derived from the "muscle scaffold theory" of Matsuoka et al. (2005), which was based on studies of mice. However, this hypothesis of muscle homology was refuted by the lack of correlation of neural crest cells and muscle origin points in non-mammalian tetrapods (Epperlein et al., 2012). Instead, it was suggested that this is a uniquely mammalian trait rather than a broad pattern present in other tetrapods.

Joyce et al. (2009) reached the conclusion that Chinlechelys tenertesta, a Late Triassic turtle from New Mexico, USA (Figure 5), unequivocally supported the composite model of carapace formation. However, this conclusion was soon discarded 


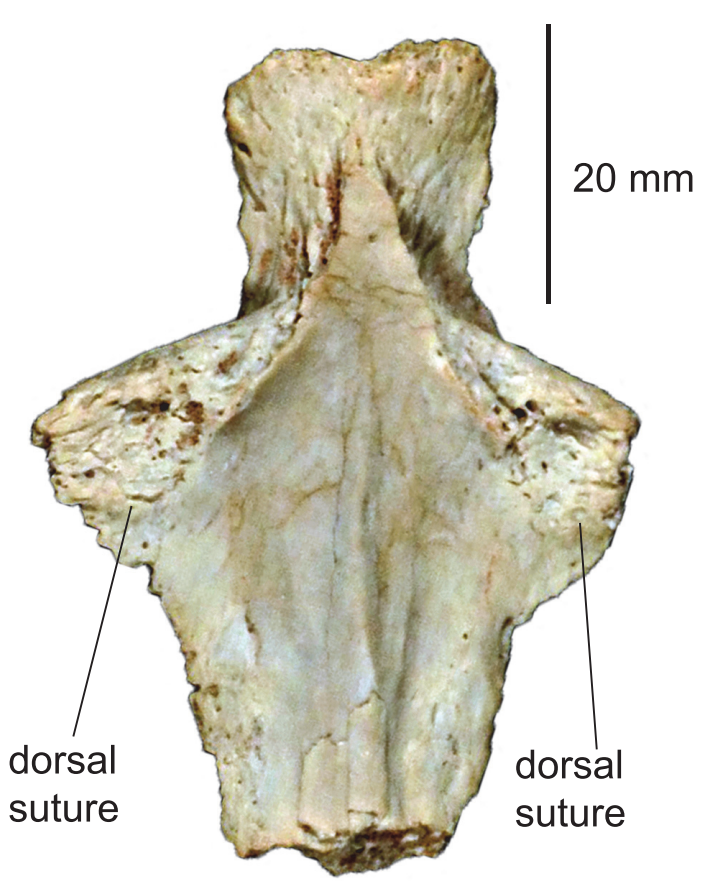

FIGURE 4. Entoplastron of Kayentachelys, Texas Memorial Museum 43687-109, showing sutures dorsally on either lateral margin of the entoplastron.

by Lyson et al. (2010, 2013b, 2016), Bever et al. (2015) and Joyce $(2015,2017)$ after the publication of Odontochelys semitestacea (Li et al., 2008). Since the publication of Joyce et al. (2009), additions to and additional preparation of the type material of Chinlechelys tenertesta have revealed numerous new details of its osteology that reaffirm its support of the composite model of carapace formation.

\section{SYSTEMATIC PALEONTOLOGY}

Chinlechelyidae fam. nov.

Type genus. Chinlechelys Joyce, Lucas, Scheyer, Heckert, and Hunt, 2009.

Included genera. Only the type genus.

Diagnosis. Turtles with the following unique features: costals not fused to the ribs, costal-costal sutures angled relative to the ribs by approximately $45^{\circ}$, additional ossifications lateral to the peripheral bones (e.g., supraperipherals), and a ventrally placed otic conch on the squamosal.

Phylogenetic definition. The most inclusive clade including Chinlechelys tenertesta but not Odontochelys semitestacea, Proterochersis robusta, or Proganochelys quenstedti.

Discussion. We consider this family worth separating as it is at least as different from Odontoche-

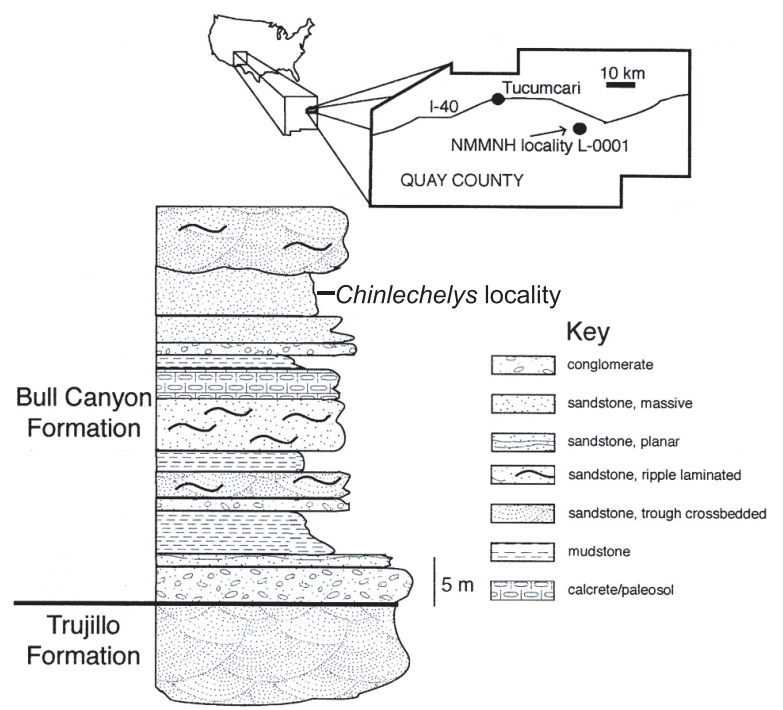

FIGURE 5. Locality and stratigraphic position of Chinlechelys tenertesta type locality. After Lucas et al. (2000).

lys and Proganochelys as Odontochelys and Proganochelys are from each other. Each of these genera, Proganochelys and Odontochelys, is placed in its own monospecific family.

\section{Chinlechelys}

Testudines indet.

Lucas et al., 2000

Chinlechelys

Joyce et al., 2009

non Proganochelys:

Joyce, 2017

Type species. Chinlechelys tenertesta.

Included species. Only the type species.

Diagnosis. Same as for family.

\section{Chinlechelys tenertesta}

Figures 6-22

Testudines indet.

Lucas et al., 2000 , p. 287, figures $2 \mathrm{~A}-\mathrm{B}, \mathrm{H}$, and 3A-B, $\mathrm{H}$

Chinlechelys tenertesta

Joyce et al., 2009 , p. 507, figures 1-2.

non Proganochelys tenertesta Joyce, 2017, p. 18

Holotype. NMMNH P-16697, incomplete skeleton consisting of the left posterior portion of the skull, central portion of the carapace, a partial left hypoplastron, various costals, portions of the bridge, posterior peripherals, supraperipherals, a left innominate, and isolated osteoderms. 




FIGURE 6. Outline drawing of Proganochelys quenstedti showing as shaded areas the approximate preserved portions of the shell and skull of Chinlechelys tenertesta. Numbers correspond to the suffix added to the specimen numbers in the text to identify specific fragments.

Type locality. NMMNHS locality 1, Revuelto Creek, Quay County, New Mexico, USA; Bull Canyon Formation, Chinle Group, Revultian (Norian), Late Triassic (Figure 5). This was a small channel in a hillside with bone spread along the surface and thus there was no block or quarry preserving their arrangement as fossilized prior to erosion (Joyce et al., 2009).

Referred specimens. NMMNH P-16621, innominate, from NMMNH locality 166; P-4315, proximal portion of a femur from NMMNH locality 53. Both of these are from localities stratigraphically equivalent to the type locality, so the stratigraphic range of Chinlechelys remains narrow.

Revised diagnosis. Same as for family.

Discussion. Joyce (2017) synonymized Chinlechelys and Proganochelys, based on the presence of supposed "neck spines" in Chinlechelys, interpreted here as posterior peripherals and supraperipherals. Nevertheless, Chinlechelys is morphologically distinct from Proganochelys in several details described in the diagnosis above (also see below). Foremost among these are the differing orientation of the ribs from the overlying costals, the ventrally placed otic notch on a broad skull, and the presence of extra ossifications distal to the peripherals (e.g., supraperipherals). Therefore, we not only retain the genus Chinlechelys but assign it to a family separate from Proganochelys.

\section{DESCRIPTION}

We describe in detail the holotype and referred specimens of Chinlechelys tenertesta, including additional anatomical details for those elements briefly described in Joyce et al. (2009) and elements not previously illustrated or discussed in print. Joyce et al. (2009) included descriptions of parts of the neurals, a hypoplastron, a lateral carapace fragment (there described as a posterior fragment), and a posterior carapace fragment (there described as cervical armor). Furthermore, a hyoplastron was mentioned but not illustrated, which is likely what we describe as a hyoplastron and mesoplastron below. All of these fossils are catalogued as NMMNH P-16697, but each of these has been given an additional identifying suffix number to facilitate future examination of morphological details (Figure 6). In addition, an innominate and a femoral head tentatively referred to Chinlechelys tenertesta are described. These bones were found near the Chinlechelys tenertesta type locality but are certainly from individuals different than the holotype.

\section{Incomplete skull roof (P-16697-12) Figures 7-8}

Further preparation has revealed a set of four bones concreted to one another and crushed so that the middle piece (prootic and opistotic) penetrates the center of the suture between the other bones. These were later separated and are seen to likely represent the left posterior portion of the skull. This assessment is based on their resemblance to known parareptile skull bones (e.g., Anthodon), and that they do not appear to correlate with the morphology of a reptile pelvis, pectoral girdle, or limb bones. The osteoderms of archosaurs known from the Chinle Group are not sutured to one another, as are the bones found with Chinlechelys postcranial elements. Furthermore, these bones do not resemble those of any other known species documented from the Chinle Group (e.g., Hunt, 2001). These bones are the quadratojugal, squamosal, jugal, prootic, and opistotic. This assessment is based on the skull arrangement of pareiasaurs, which places an elongate quadratojugal at the lateral posterior margin of the skull, with the squamosal and jugal more medially placed and sutured to this (Lee, 1994). The posterior edges of the quadratojugal and most of the squamosal are missing, but the outline of a distinct cephalic emargination is preserved on the medial portion of the squamosal.

The quadratojugal is $31 \mathrm{~mm}$ long, $16 \mathrm{~mm}$ wide, and $17 \mathrm{~mm}$ high, which is unusually long for a turtle. Even missing its posterior margin, it is two times longer than dorsoventrally thick. The cross 
section of the quadratojugal approximates an isosceles triangle, with the base on the proximal side toward its posterior end. Anteriorly, this is interrupted by a ventrally located longitudinal ridge of bone smoother than the rest of the surface. At the anterior end there is a lateral, raised ridge with a triangular cross section. At the proximal ventral margin there is a flange of flat bone projecting $\sim 4.6$ $\mathrm{mm}$ ventrally, with its posterior and anterior ends broken off. This bone could be one of a couple of elements, including the paroccipital process or a part of the mandibular process of the quadrate. Unfortunately, it is not possible to identify this structure with confidence.

The jugal is missing its medial and anterior margins and measures $21.5 \mathrm{~mm}$ long and $23 \mathrm{~mm}$ wide. The triangular, raised ridge on the quadratojugal continues onto the anterior portion of the jugal, terminating at the base of a conical dorsal process whose base measures $15 \mathrm{~mm}$, long, $8 \mathrm{~mm}$ wide, and is at least $6 \mathrm{~mm}$ tall with the tip missing (Figure 7). This process resembles the "horns" of Anthodon and Nanopareia's jugal and squamosal. Posterior to this ridge is another ridge that is angled $70^{\circ}$ counterclockwise from it, running from the more dorsal process into the quadratojugalsquamosal suture. Another similar ridge runs posteriorly from the posterior end of the dorsal process onto the squamosal to the base of the posterior, conical dorsal process. The processes on the ventral surface of the squamosal and jugal appear to outline the left posterior portion of the braincase.

The squamosal is $26 \mathrm{~mm}$ wide, minus its posterior end, and it is at least $16 \mathrm{~mm}$ long. The medial edge is smooth, and this is the original edge of a distinct temporal emargination. Dorsal to this margin are the posterior dorsal conical process and a process most likely sutured to the parietal. The ventral portion of this process has a longitudinal sulcus meeting a parallel raised ridge just dorsal to the ventral margin of the bone. On the lateral posterior edge of the squamosal there is an elliptical, cone-shaped opening facing ventral-posteriorly that we identify as the ventrally facing depression we term an otic conch (Figure 8). This is based on the possession of an otic notch formed by the squamosal and quadrate in Proganochelys and Odontochelys (Gaffney, 1990; Li et al., 2008) as well as the lack of similar notches on the posterior end of the skull of other known basal turtles. This notch has variously been referred to as the quadrate lateral conch, lateral conch, or cavum tympani in previous publications (e.g., Gaffney, 1990; Reisz and Laurin, 1991). An important note is that there is a small change in texture along a distinct line in this fragment that may indicate it is actually two bones. The second and ventral of these would be the quadrate, and this would fit with the presence of the otic conch and a small articular surface near the anterior end of the fragment. Given the uncertainty of the identification of the bone this structure is located on, we use the term otic conch.

The prootic and opistotic (Figure 8.3) are incompletely preserved, missing both ends. Originally, the prootic and opistotic had been pushed through the triple junction between the squamosal, quadratojugal, and jugal, so that only the portion of these bones between the bones of the skull roof remain. Another possibility is the paroccipital process, but the lack of a rounded, finished end makes this unlikely. The remaining portion is robust, measuring $18 \mathrm{~mm}$ long, $12.5 \mathrm{~mm}$ wide, and $6.5 \mathrm{~mm}$ thick, tapering toward one end. The cross sections of the bones are slightly triangular with rounded edges. A sulcus runs the length of the bone on the point of the triangle opposite the longest side.

\section{Partial Carapace and Vertebral Column (P- 16697-8 and-15-16) \\ Figures 9-13}

Recently discovered additions to the morphology of the holotype of Chinlechelys tenertesta are bones of the midline of the carapace including eight thoracic vertebrae. The vertebrae begin with a reduced first thoracic vertebrae, as in Proganochelys quenstedti, and continuing to a nearly complete eighth (Figure 9). The ventral process of each centrum narrows posteriorly, as does the neural canal. The ribs articulate with each centrum just posterior to their suture to the preceding centrum. The dorsal surface of the centrum is not in contact with the rib, forming a broad opening on either side of the neural arches before the rib meets the neural plate laterally (Figure 10.3).

The centra are roughly rhomboidal, in anterior or posterior view, with the vertical dimension longer than the horizontal. Furthermore, the central articulations are platycoelus and about the same size as the neural canal. The centra are greatly widened toward their dorsal ends, with a thickness of as little as $1.5 \mathrm{~mm}$ toward their dorsal ends and a height of $18.5 \mathrm{~mm}$. The neural arches have a joint with clear separation from the overlying neurals similar to that of the ribs to the costals as seen in anterior view.

The first thoracic vertebra, partially preserved, is $6 \mathrm{~mm}$ long and does not have the rib preserved 


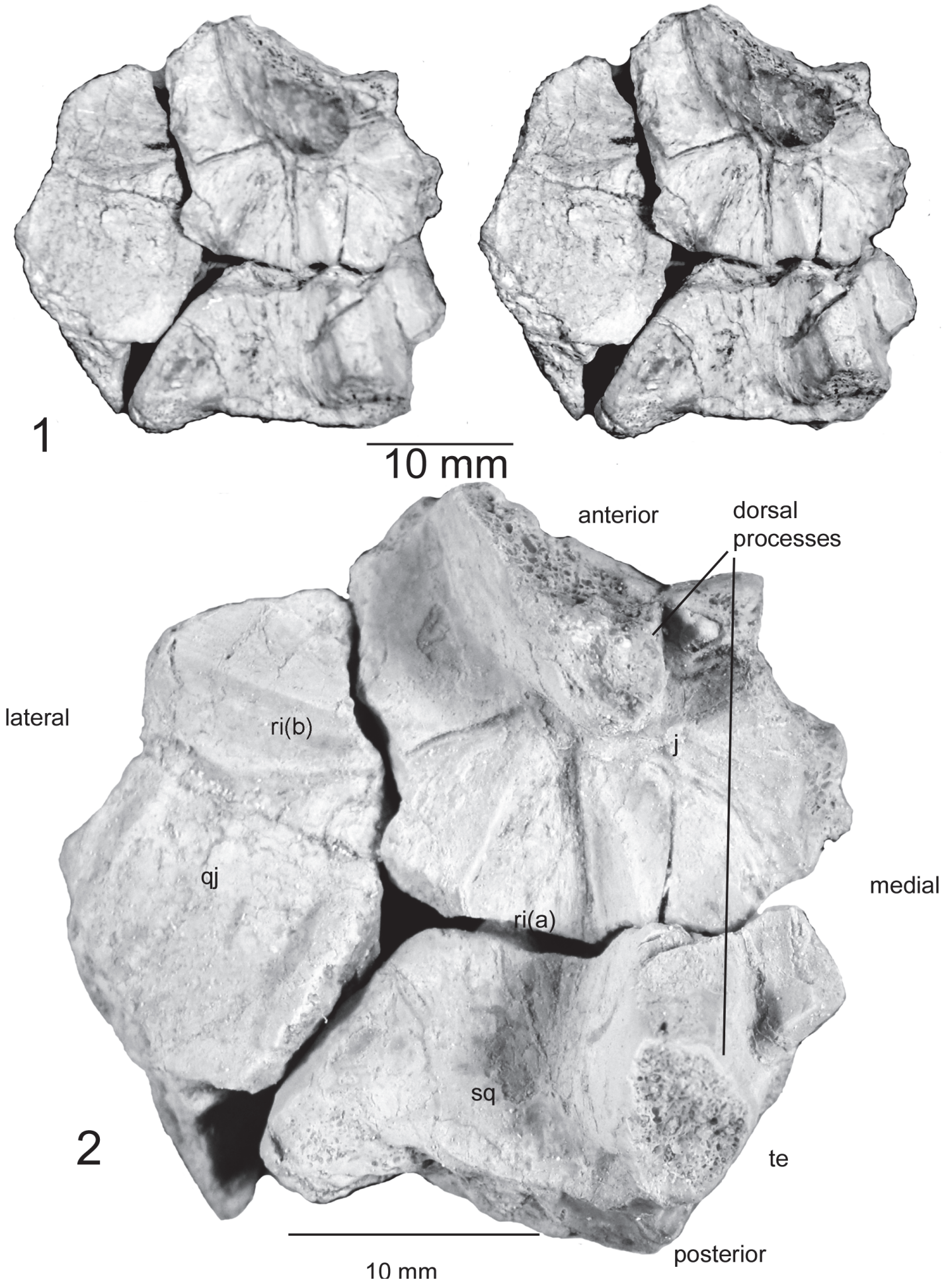

FIGURE 7. Part of skull of Chinlechelys tenertesta, NMMNH P-16697-12: 1, stereograph of the left posterior portion of Chinlechelys skull in dorsal view; 2, dorsal view of same with labels. Abbreviations: po, jugal; qj, quadratojugal; ri, ridge ( $\mathrm{a}$ and $\mathrm{b}$ indicate the two separate ridges referred to in the text); sq, squamosal; te, temporal emargination. 

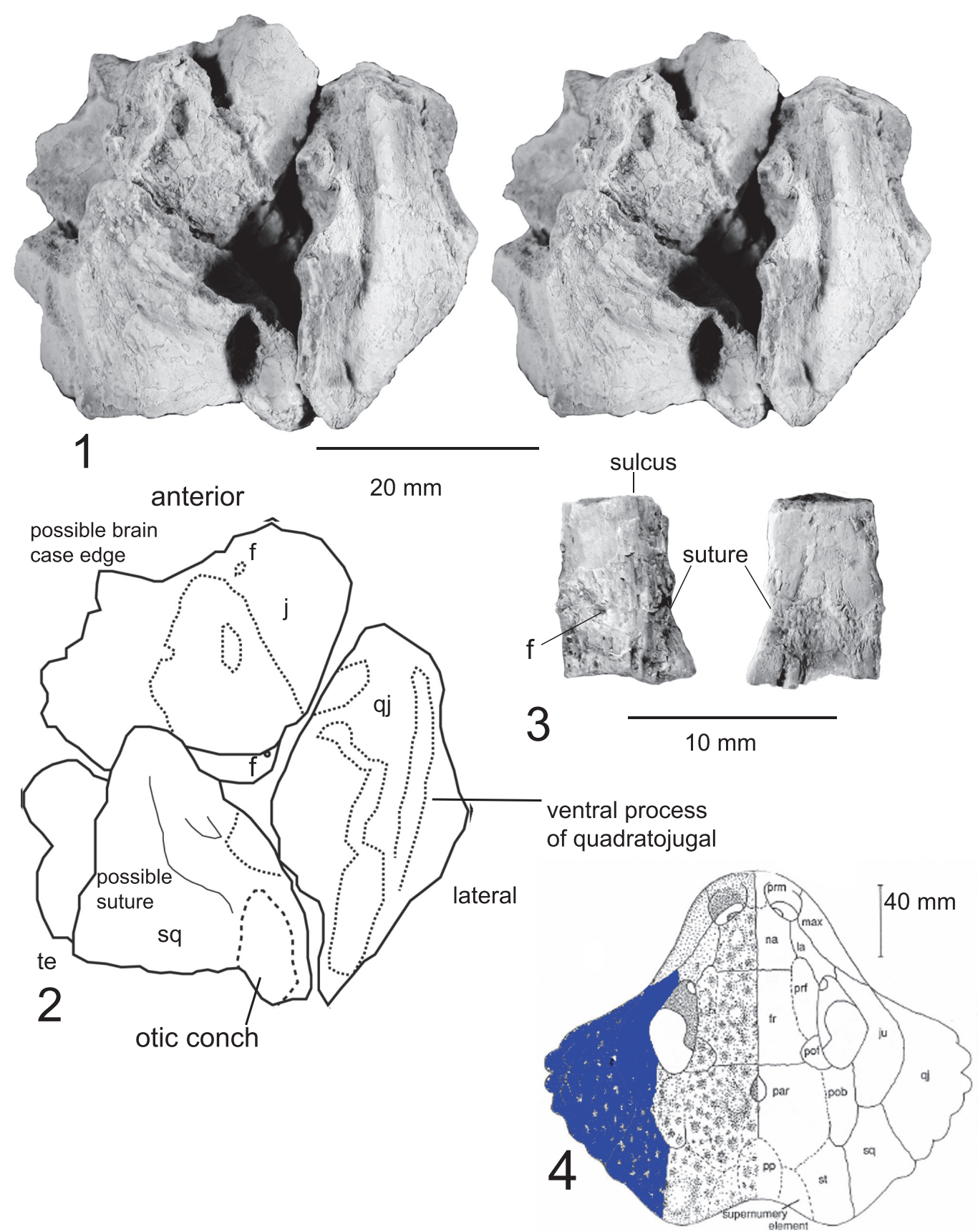

FIGURE 8. Part of skull of Chinlechelys tenertesta, NMMNH P-16697-12: 1, stereograph of the left posterior portion of Chinlechelys skull in ventral view; 2, line drawing highlighting major features of the skull fragment; 3, prootic and opistotic viewed from opposite sides, orientation unknown; 4, skull of Anthodon serrarius modified from Lee (1993) with the bones corresponding to those identified in Chinlechelys highlighted. Abbreviations: po, jugal; qj, quadratojugal; sq, squamosal; te, temporal emargination.

(Figure 10). The neural canal is large $(4.7 \mathrm{~mm}$ wide and $3.5 \mathrm{~mm}$ high) compared to other parts of the specimen. The area surrounding the neural arch is absent, so the anatomy of this area is unknown. The first thoracic vertebra is sutured to the following second thoracic vertebra, but still loose enough that some post-death dorsal movement is apparent.

The second thoracic vertebra is $20 \mathrm{~mm}$ long and $9.8 \mathrm{~mm}$ wide at its narrowest point, preserving its full length (Figure 10). The centrum has a diamond-shaped cross section, with a distinct dorso- 


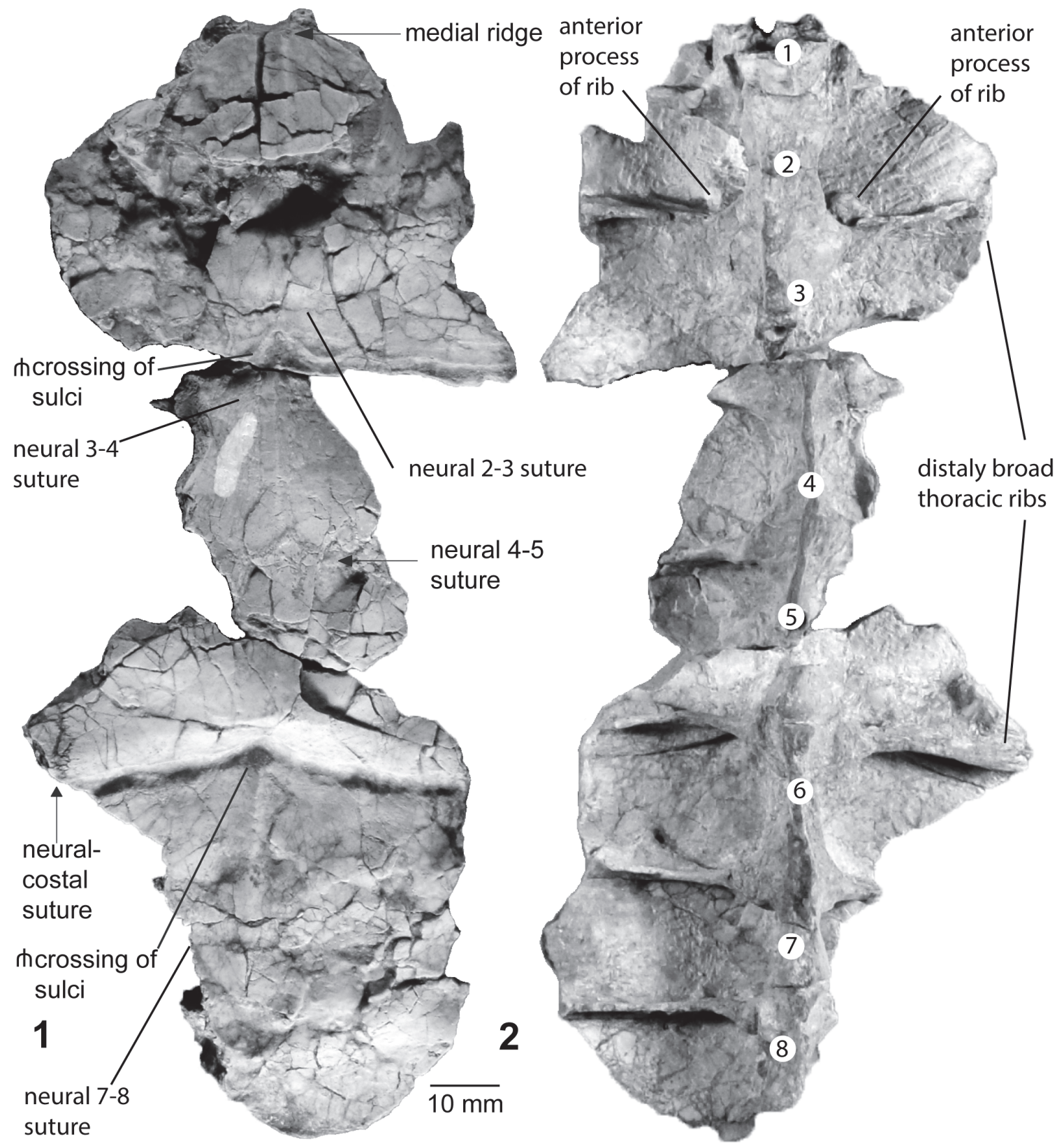

FIGURE 9. Chinlechelys tenertesta NMMNH P-16697-8,15,16, Neural plates and thoracic vertebrae 1-8 in 1, dorsal; and 2, ventral views.

lateral concavity along the length between the rib articulations. The first preserved rib (second thoracic) has a broad triangular base, articulating with both the first and second thoracic vertebrae. The contact with the first thoracic is slightly thicker, giving a wedge-shaped cross section to the base of the rib. No contact with the costal plate is preserved. The distalmost preserved portion of the rib has an unusual, figure-8-shaped cross-section compared to the T-shape of the other ribs. The overlying neural plate is smooth, with a medial ridge that reaches its highest point just anterior to the articular surface between thoracic vertebrae 1 and 2.

The third thoracic vertebra is partially preserved, missing the ventral-posterior portion of the centrum (Figure 10). No rib is preserved, but the overlying neural plate is well preserved. This has a clear neural-neural suture, angled $\sim 10^{\circ}$ posteriorly. The midline ridge from the previous neural contin- 


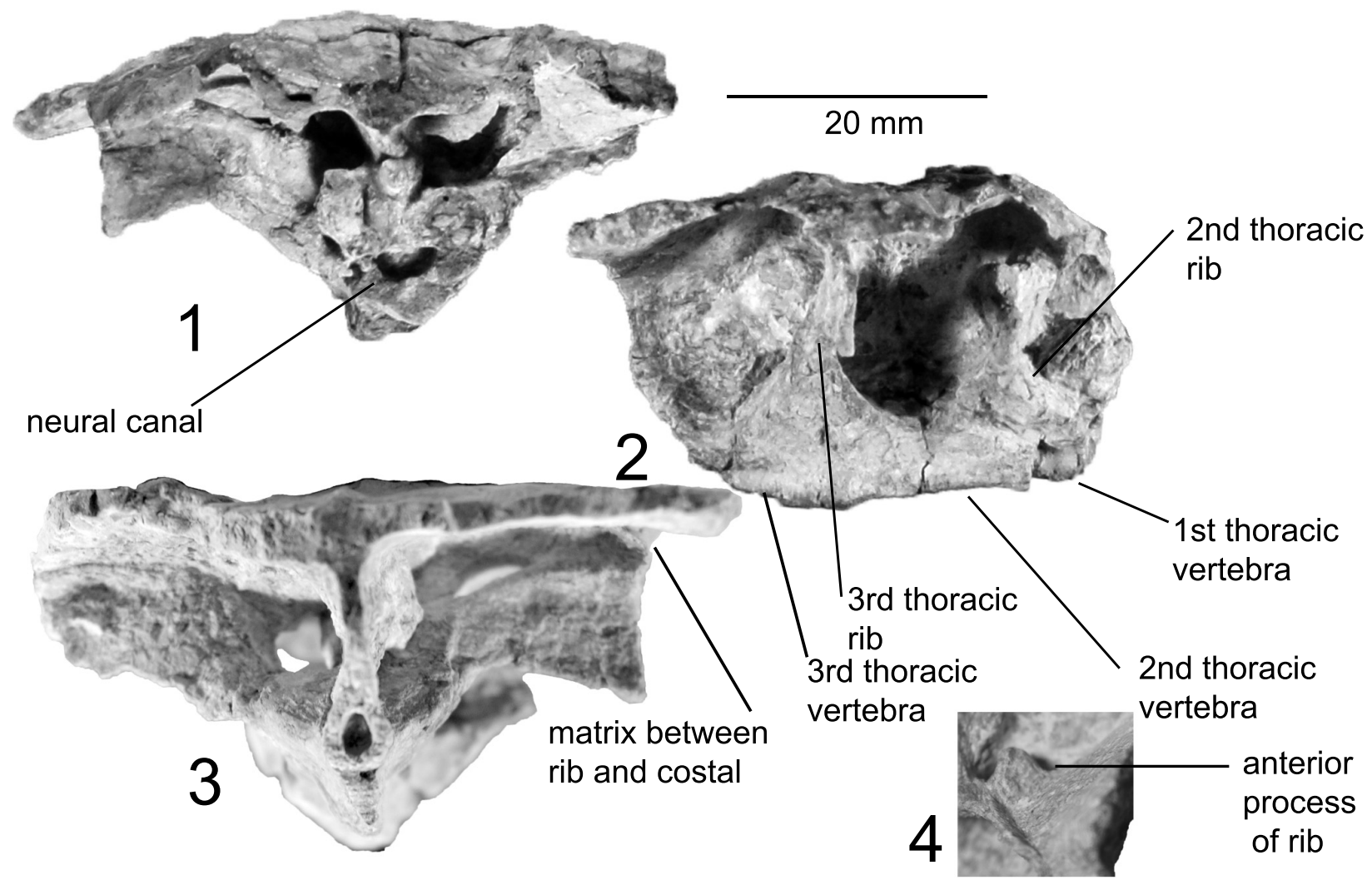

FIGURE 10. Chinlechelys tenertesta NMMNH P-16697-15, Neural plates and thoracic vertebrae 1-3 in 1, anterior; 2, right lateral; 3, posterior views; and 4, a close up of the anterior process of the right rib 3.

ues to $\sim 3 \mathrm{~mm}$ posterior to this where it is crossed by a lateral sulcus with a raised anterior edge, as in other Chinlechelys sulci. This sulcus and the medial ridge form a "trident $(\psi)$ "-shape, with the three points facing posteriorly and the handle anteriorly (Figure 9.1). In the center of this, the midline ridge is almost flat but becomes more prominent posteriorly; thus, it is a prominent ridge seen above the fourth thoracic rib only $3 \mathrm{~mm}$ posterior to this junction. The second preserved rib contacting thoracic vertebrae 2 and 3 has a broad triangular base, $15 \mathrm{~mm}$ long at the suture to the centrum. This suture is $13 \mathrm{~mm}$ high, forming a broad attachment to the centrum, but still leaving a $6.5 \mathrm{~mm}$ gap between the top of this suture and the neural plate. Distally the rib articulates with the costal plate $\sim 8$ $\mathrm{mm}$ from the articulation of the centrum and the neural plate. At this point the dorsal surface of the rib broadens, forming the characteristic T-shaped cross section of basal turtle ribs. The rib has an anterior process just distal from the articulation to the centrum, and this curves toward a bulge on the top of the centrum. The neural and costal plates between these ribs have been slightly warped downward taphonomically and significantly frac- tured, obscuring fine details, but there appears to be a slightly lower medial ridge continuing through this portion of the carapace. The greater length of the neural plate relative to the underlying centrum indicates that at least some of the downward curvature preserved in this area is original and not the result of taphonomic distortion, but the exact curvature is unknown.

Thoracic vertebrae 4 and 5 (Figure 11) were described and illustrated in Joyce et al. (2009, figures 1a-f and 2a-f), except for the presence of a suture on the surface of the neural plate described here. Overall, the fragment is $42 \mathrm{~mm}$ long, 30.5 $\mathrm{mm}$ wide, and $29.5 \mathrm{~mm}$ high. The more complete of the two neurals is $21.5 \mathrm{~mm}$ long on its ventral margin and $\sim 24 \mathrm{~mm}$ long on its dorsal margin. There is a distinct dorsal medial ridge on this bone. This ridge becomes more pronounced toward the anterior end of the bone.

The suture between the two neural plates comes to an anterior facing point near the midline just anterior to the posterior rib. The point forms a $\sim 95^{\circ}$ angle, leaving an $\sim 47^{\circ}$ angle on either side similar to the angle between the ribs and the costal-costal suture in P-16697-3 (Figure 13.3-5). 




FIGURE 11. A-D, Chinlechelys tenertesta NMMNH P-16697-8: Two neural plates and vertebrae in 1, lateral; 2, dorsal views; 3, anterior; 4, posterior; and 5, dorsal outline drawing. Abbreviation: $\mathrm{n} 1$, first anterior neural; and n2 second neural; r, rib; and rid, medial ridge.

Each rib is just anterior to the articulation with the following centrum. The neural plates are fused to the neural spines of the dorsoventrally elongate centrum, meeting the neural plate with no clear point of separation. The fifth thoracic vertebra includes a portion of the neural plate where the medial ridge becomes low, to the point of being absent.
The sixth thoracic vertebra is well preserved and $21.6 \mathrm{~mm}$ long, with a broadened portion just ventral to the neural plate (Figure 12). The neural plate above this has a strong step just posterior to the neural 5-neural 6 suture, curving ventrally nearly $1 \mathrm{~cm}$. Along the midline, a $\psi$-sulcus juncture is formed similar to that seen on the third thoracic vertebra. A neural-costal suture is preserved 28 $\mathrm{mm}$ to the left of the midline ridge on the anterior 


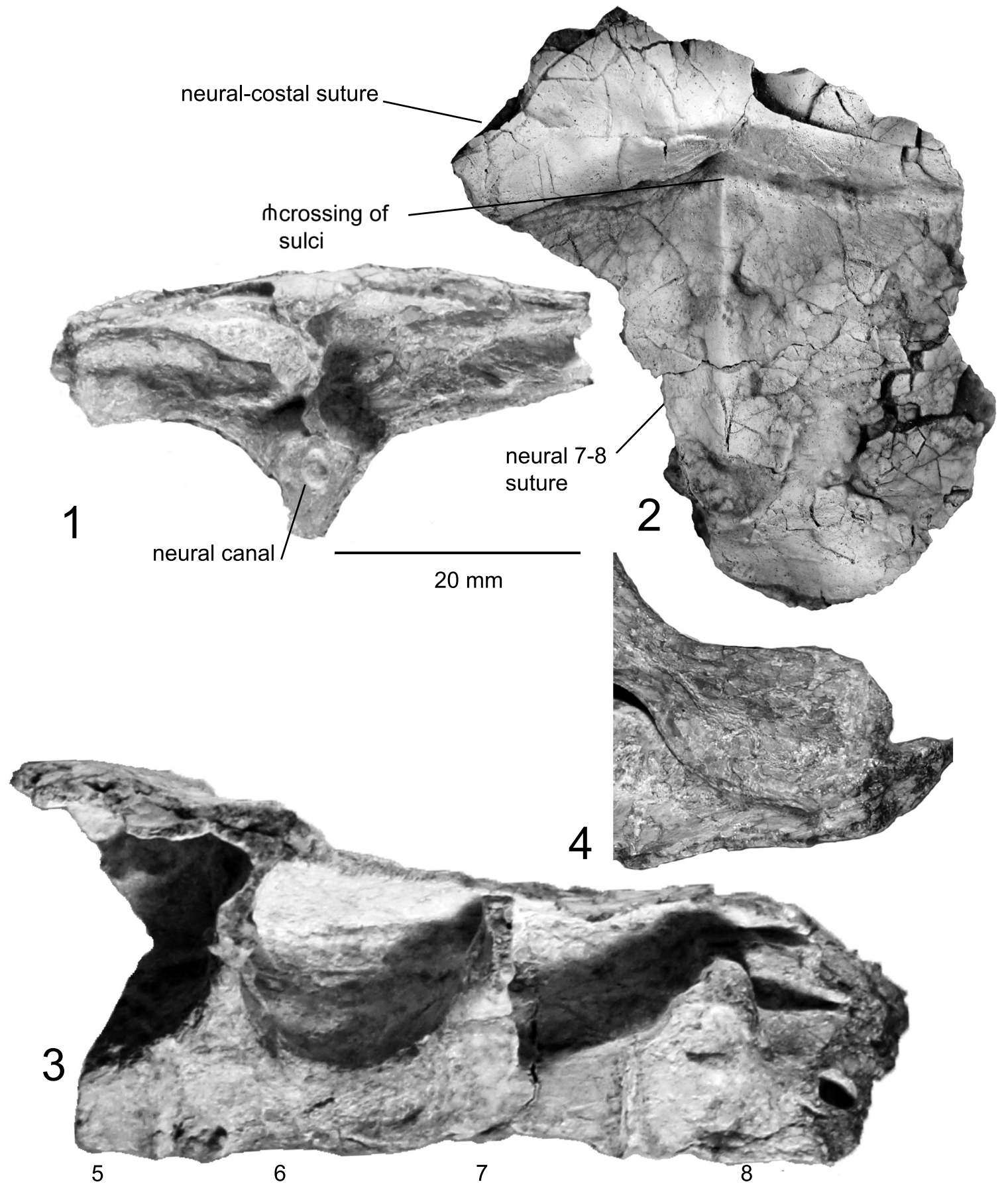

FIGURE 12. Chinlechelys tenertesta NMMNH P-16697-16 Neural plates and thoracic vertebrae 5-8 in 1, anterior; 2, dorsal; 3, left lateral views; 4 , close up of thoracic rib highlighting the separation from the overlying costal plate. Numbers indicate the thoracic vertebrae positions.

portion of the step. The rib articulating to the anterior part of the sixth thoracic vertebra is slightly concave posteriorly and reaches the neural/costal plate with a minimally broadened dorsal surface. At this point, the dorsal portion of the rib broadens more on the posterior side than on the anterior side. At its broadest point, it is still less than $20 \%$ of the length of the associated centrum, leaving broad gaps between the ribs. The seventh thoracic verte- 



FIGURE 13. Chinlechelys tenertesta costal, NMMNH P-16697-1 in 1, Dorsal and 2, ventral views; 3-5, Costals and ribs P-16697-3: 3, Ventral view and 4, line drawing; 5, Close up of dorsal side of rib in $\mathrm{F}$ where the costal plate has been broken away; and 6, Lateral view. Abbreviations: r, rib and c, costal.

bra is more lightly built than the sixth and has a narrower associated rib, but is otherwise similar.

The eighth thoracic vertebra (Figure 12) is similar to the seventh but is yet more gracile. Perhaps this is the result of the narrowing of the shell and the corresponding reduction in mass that needs to be supported by the underlying vertebrae. The T-shape of the rib is shorter than the other preserved ribs; only 1.5 times as long as wide. The sixth through eighth ribs appear to lack the anterior process seen on the first and second ribs (Figure 12). The anterior process of the rib is not preserved on thoracic ribs 3-5, so the location and nature of this transition is unclear.

\section{Costal (P-16697-1) Figure 13.1-2}

An isolated, partial costal is a thin bone that is concave ventrally with a part of a rib running transversely across its ventral surface. The rib is strongly curved anteriorly. At the proximal end, the rib and costal appear distinct. The rib has a triangular profile and is widest where it meets the costal. The costal plate is $25 \mathrm{~mm}$ long and $31 \mathrm{~mm}$ wide, with no visible sulci.

\section{Two Costals (P-16697-3) Figures 13.3-6, 14}

This fragment of the carapace includes parts of two costals and two ribs located toward the proximal end of the costal bones. The costals are of nearly uniform thickness, with a finely sculptured 


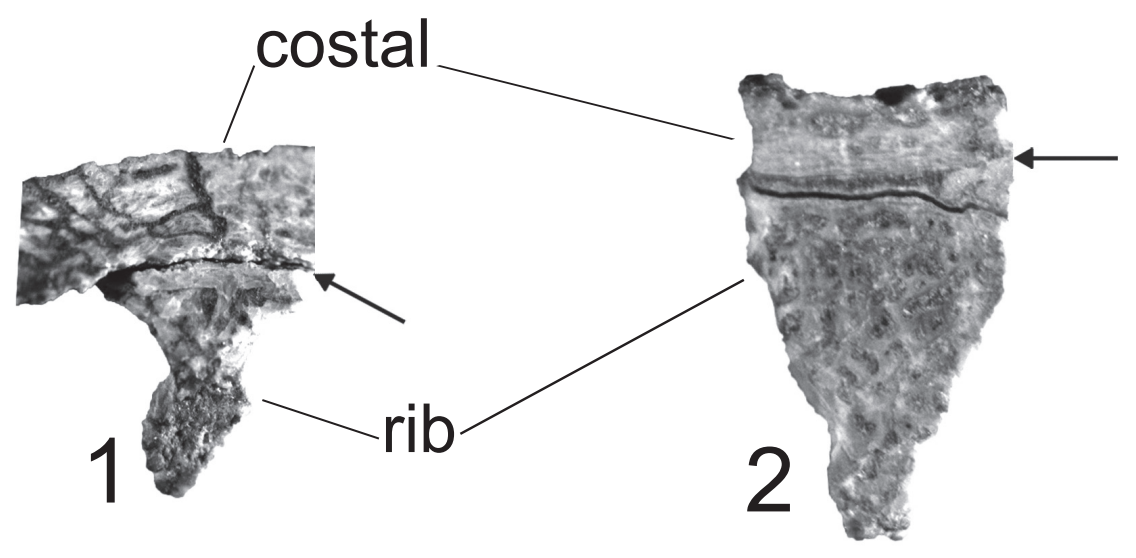

\section{$5 \mathrm{~mm}$}


\section{5}

6

FIGURE 14. Chinlechelys tenertesta costal, NMMNH P-16697-3: 1, Close up of a cross section across the rib of NMMNH P-16697-1 on the right in Figure 12.6; and 2, cross section of rib on the left in Figure 12.6. 3, color close up of a cross section across the same rib of NMMNH P-16697-1 seen in 14.1; 4 , color close up of a cross section across the same rib of NMMNH P-16697-1 seen in 14.2; 5, progressive ct scan slices through the rib in figure 14.1; and 6, progressive ct scan slices through the rib in figure 14.2 . 
surface. The ribs are $4.8 \mathrm{~mm}$ wide and $5.3 \mathrm{~mm}$ high, narrowing slightly distally. There is a strong bend in the costals at an approximately $45^{\circ}$ angle to the ribs. Furthermore, a suture between the two costals runs $45^{\circ}$ to the ribs in the opposite direction, forming a nearly $90^{\circ}$ angle with this bend. Given the high angle between the ribs and the sutures of the costals, we interpret them to be separate structures.

We polished the edge of a fragment, including parts of two costals, to allow examination of the connection between the ribs and the costal bones (Figures 13.3-4, 14.1-2). The fragment measures $39 \mathrm{~mm}$ long and $23 \mathrm{~mm}$ wide, with two ribs. Both polished rib ends show a slight separation from the costals (Figure 14.1-2). This separation has compact bone on both sides, so this is not a secondary fracture but instead represents the true separation of two anatomical elements. This is supported by the morphology of a small segment of the dorsal surface of the rib exposed where the costal plate has been broken away (Figure 13.5). The rib has a ridged surface with no trace of fractures along its joint with the costal plate. Instead, a set of longitudinal ridges is present, similar to those reported for the ribs of Odontochelys semitestacea ( $\mathrm{Li}$ et al., 2008), which appear to interdigitate with the costal plate. There are two dark bands visible in Figure 14.1. These bands are quite distinct in their morphology and origin. The lower band is a fracture, it crosses parts of the bone microstructure and forms a deep void. The bone on either side of this void is similar. Conversely, the first line indicated by an arrow as a suture has no depth or void along its surface and lies along a distinct change in bone microstructure. This change in microstructure creates the change of shade seen in the image. This, as well as the fact that the ribs and costals are not remotely parallel, leads to the conclusion that they are distinct elements that are unfused in Chinlechelys tenertesta.

\section{Costal (P-16697-5) Figure 15.6-7}

This fragment is a piece of bone including parts of three costals with strongly curved sutures between them. This fragment contains a longitudinal ridge running across parts of two costals. We interpret this as a dorsal ridge, as a ventral placement would impede locomotion by catching on passing objects. Furthermore, no such ridges are known on the plastra of other turtles. This ridge is $31 \mathrm{~mm}$ long on a $34 \mathrm{~mm}$ wide fragment. To one side, the carapace drops off slightly, then it curves back parallel to the surface opposite the ridge. The sutures between the three costals curves anteriorly where it crosses this dorsal ridge The orientation of this fragment is inferred from the angle of the sutures relative to those near the midline. An alternative interpretation would be that this might be a fragment of the plastron side of the bridge. In this case one or more of these ossifications might be mesoplastron.

\section{Carapace Element (P-16697-2) Figure 15.1-2}

A small fragment comes from the carapace. We base this placement on the presence of a spiny protuberance that would interfere with locomotion if placed on the plastron. The orientation of the fragment is inferred based on the presumption that the overhanging spine is posteriorly facing as in most animals' dorsal spines. The fragment consists of four bones (osteoderms) in two rows of two separated by digitate sutures. The left two are $15 \mathrm{~mm}$ wide, missing their left edges and are 9 and $13 \mathrm{~mm}$ long. The posterior of these has a prominent protuberance at its posterior edge, which is preceded by a ridge running to the anterior edge of the fragment. Just a small corner of the bone on the right anterior side of the fragment is preserved. The posterior right bone is at least $17 \mathrm{~mm}$ long and $13 \mathrm{~mm}$ wide, coming to a point at the suture between the two left osteoderms. The osteoderms broaden posteriorly.

\section{Costal Elements (P-16697-6 and -7) Figure 15.3-5}

Two small fragments show small, conical projections on their dorsal surfaces. These have a rib fused to the ventral side of the costal. The first fragment (Figure 15.3-4) measures $17 \mathrm{~mm}$ long and 20 $\mathrm{mm}$ wide, with the projection oriented nearly parallel to the rib. The rib is "T" shaped in cross section and clearly visible on the ventral side of the costal.

The second fragment (Figure 15.5) is narrower and has one side of the protrusion nearly perpendicular to the surface of the costal. The fragment has a nearly flat visceral surface measuring $22 \mathrm{~mm}$ long by $34 \mathrm{~mm}$ wide (orientation based on raised structure presumed to run laterally) and includes a raised structure, likely a rib. A suture runs about $45^{\circ}$ to this, dividing the fragment into two ossifications - a rib and a costal. The element is thickened toward the corner close to this raised structure. 

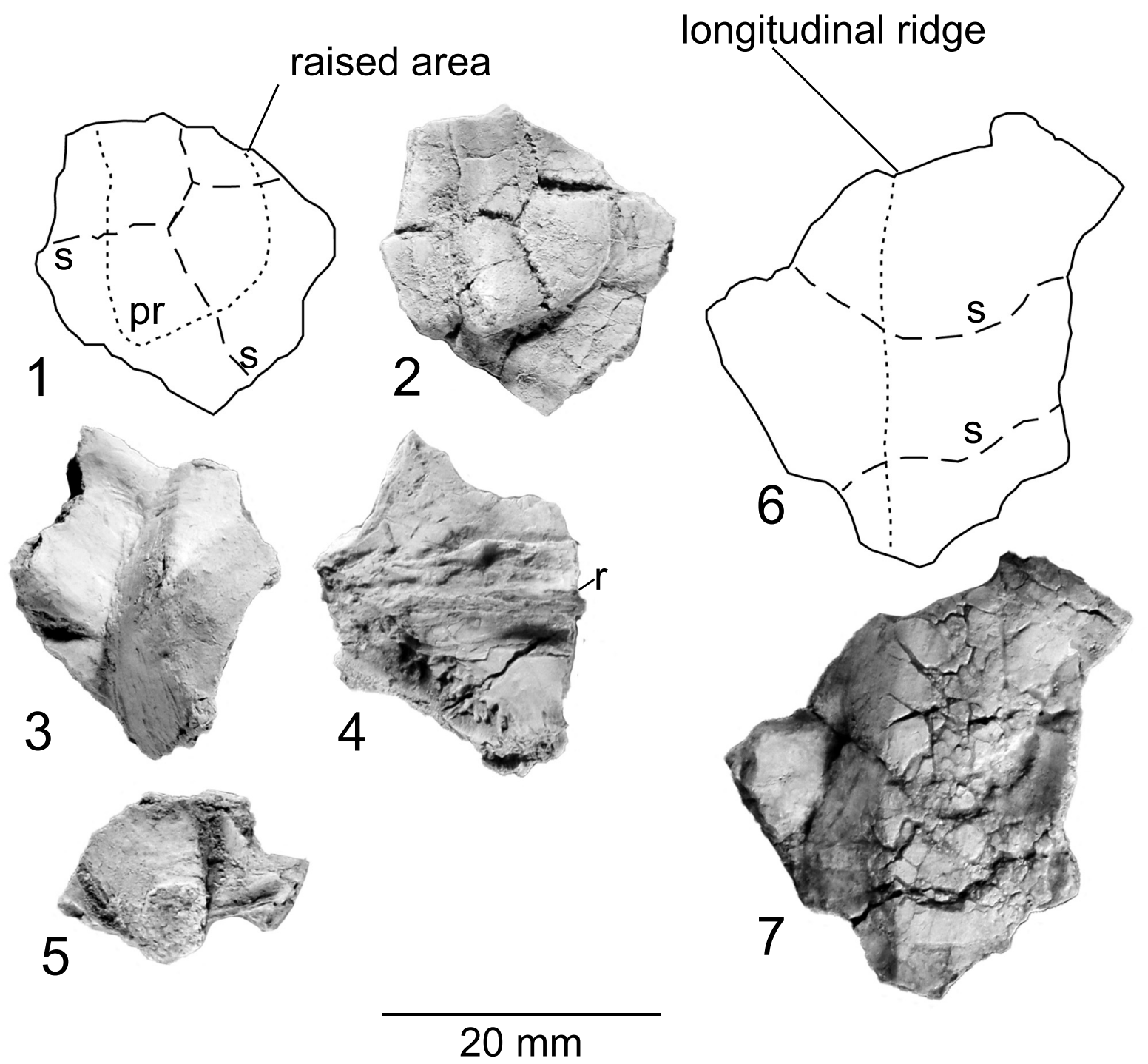

FIGURE 15. Carapace fragments of Chinlechelys tenertesta: 1-2, NMMNH P-16697-2 costal bones in dorsal view; 34, NMMNH P-16697-6, costal fragment in dorsal and ventral views; 5, NMMNH P-16697-7, costal fragment in dorsal view; and 6-7, NMMNH P-16697-5 costal fragment in dorsal view. Abbreviations: pr, dorsal process; r, rib; and s, suture.

\section{Costals and peripherals (P-16697-10) Figure 16}

Joyce et al. (2009, figures $1 \mathrm{~g}, 2 \mathrm{~g}$ ) illustrated and described a fragment they identified as a costal, ribs, and a posterior peripheral. In addition to what was included in Joyce et al. (2009), further preparation has added other peripheral and costal fragments. Sutures divide the costal portion into four bones- two matching the two peripherals and two bones of uncertain identity proximal to the cos- tal but with no indication of the thickening nearer to the neural. Given that the fragment is much narrower than the hypoplastron far from the midline, the possibility that this fragment represents a row of costal plate ossifications in addition to the usual single row would appear to be a distinct possibility.

The orientation of this fragment was assessed based on the orientation of the costal sutures in P16697-3. From this we infer that the lateral edge of this fragment is approximately perpendicular to the midline. This is supported by the presence of a dor- 

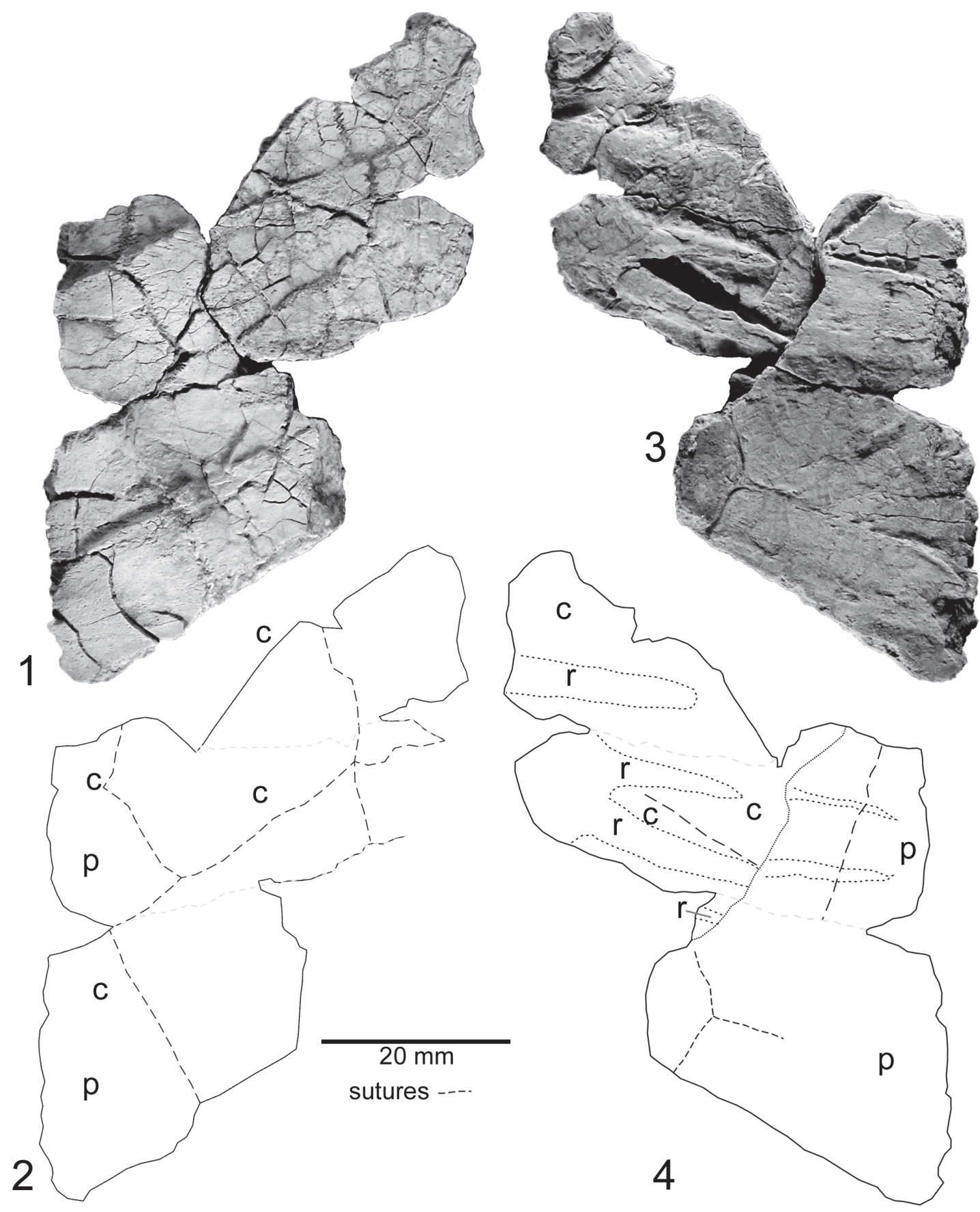

FIGURE 16. Chinlechelys tenertesta, NMMNH P-16697-10, Costals and peripherals: 1, Dorsal view; 2, line drawing of dorsal view; and 3-4, ventral view. Abbreviations: c, costal; p, peripheral; and r, rib.

sal and ventral portion of the peripheral merging at the lateral edge, which appears to be the bridge of the shell. Of note is that there are four, rib-like structures in only $26 \mathrm{~mm}$ of the peripheral's length in this fragment, with the two included in Joyce et al. (2009) seeming to converge medially. An impression or raised portion similar to these two ribs and parallel to them is visible in the lower plate of the peripheral.

Triangular armor-"supraperipherals" (P-166979)

Figure 17

Remains of two sharp boney spikes were the first Chinlechelys tenertesta material collected and 

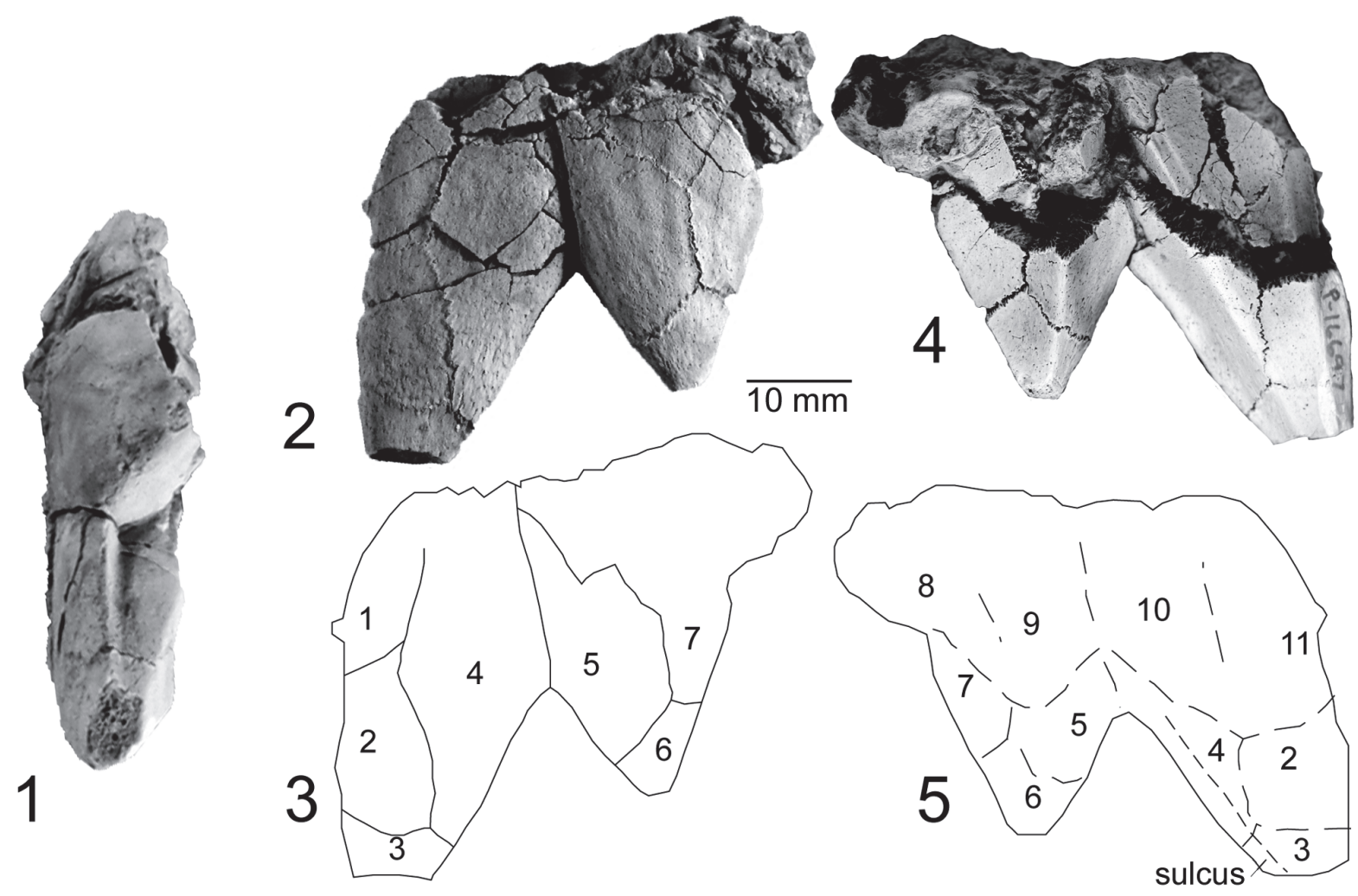

FIGURE 17. Chinlechelys tenertesta, NMMNH P-16697-9: Peripherals and supraperipherals in 1, lateral; 2, dorsal; and 4, ventral views. 3, dorsal line drawing; and 5, ventral line drawing. The ossifications labeled 1, 4, 5, 7, 8, 9, 10, and 11 forma a continuous line we consider equivalent to peripherals. The ossifications labeled as $2,3,6$, and 7 are additional ossifications distal to these which we term supraperipherals.

described (Lucas et al., 2000). They have had a controversial anatomical placement. These spikes have been hypothesized to either represent a part of the neck armor, as in Proganochelys quenstedti (Lucas et al., 2000; Joyce et al., 2017), or possibly a portion of the margin of the carapace (Joyce et al., 2009; Szczygielski and Sulej, 2019). We suggest that the latter is more plausible, based on the differences in shape from the neck armor of Proganochelys quenstedti, the presence of sulci, not known to occur on such neck armor (Gaffney, 1990) as well as the presence of radial surface sculpture similar to that seen on the posterior peripherals of Proganochelys quenstedti (Gaffney, 1990, fig. 74). Furthermore, these spikes are larger relative to the neck spines of Proganochelys quenstedti and the size of the remaining Chinlechelys tenertesta bones, so that these would have to be even larger (approximately double the width of) neck spines than are seen on Proganochelys quenstedti. Thus, we posit that this is a fragment of the posterior margin of the carapace displaying six "supraperipherals". We define the term supraperipheral to indicate additional ossifications distal to the row of peripherals normally present on the turtle's carapace.

The total fragment is $34 \mathrm{~mm}$ long and $44 \mathrm{~mm}$ wide, with two distinct triangular spines. The larger of these has a trapezoidal cross section, with the longest convex side dorsally and an overall triangular shape. Sutures divide this spine into at least five osteoderms, with one osteoderm forming the tip, as two pairs of osteoderms of increasing size medially form the more proximal portion of the spine. The side facing the smaller spine is strongly concave, forming an acute dorsal edge. On the ventral surface, paralleling the corner joining the edge facing the smaller spine, a sulcus indicates the presence of an overlying horny scute.

The smaller spine is triangular in both cross section and overall shape. It is composed of four osteoderms-one at the tip, a pair proximal to this, and a single osteoderm forming a triangle between these two at the proximal edge of the fragment. Again, the dorsal surface is convex, with the ventral surface concave, forming acute angles at the margins. 




FIGURE 18. Chinlechelys tenertesta, NMMNH P-1669713, hyoplastron and mesoplastron in 1, external view; 2 , external view line drawing; and 3, internal view. 4, left axillary notch in dorsal view. Short dashes indicate sutures and longer dashes sulci and raised surface structures.

\section{Hyoplastron and Mesoplastron (P-16697-13) Figure 18.1-3}

This bone was briefly mentioned by Joyce et al. (2009) as a possible hyoplastron fragment. Further preparation revealed its composite nature including multiple ossifications. The right hyoplastron is preserved, measuring $21 \mathrm{~mm}$ long near the medial portion of the fragment, and $59 \mathrm{~mm}$ wide. The mesoplastron sutures to the posterior edge of this element, with a similar width. It measures 22 $\mathrm{mm}$ long nearest the midline and narrows laterally to $9.5 \mathrm{~mm}$ posterior to the opening of the axillary notch. A lateral sulcus runs nearly parallel to this suture, becoming further distanced from the posterior margin approaching the midline. There is also a raised longitudinal structure near the medial edge of this fragment that curves antero-laterally, varying in thickness, so that this structure reaches its greatest width approximately halfway along its preserved length. Most of the bone is $\sim 2 \mathrm{~mm}$ thick, increasing in thickness towards the inguinal notch and the bridge. In addition, on the visceral surface of the bone there is a rounded and raised structure running from the right posterior edge of the fragment antero-medially along the anterior edge of the mesoplastron. This reaches its greatest thickness of $7 \mathrm{~mm}$ at a point $\sim 26 \mathrm{~mm}$ medial to the medialmost preserved portion of the inguinal notch, opposite a concavity in the external surface.

\section{Mesoplastra (P-16697-4) Figure 19.1-3}

Another fragment has been revealed by preparation to consist of four separate osteoderms. We interpret this fragment to be from the mesoplastron, as it is nearly flat and possesses a thickened, presumably lateral edge, as in the hyo- and hypoplastron, with no thinning of the bone toward the anterior or posterior end. Furthermore, it fits the pattern seen in basal turtles where more basal turtles have a higher number of mesoplastra (e.g., Odontochelys semitestacea has four [two pairs] but Proganochelys quenstedti only has two [one pair]). An alternative interpretation is that this is part of the xiphiplastron, but the lack of thinning toward one end does not support that interpretation. One of the corners of this fragment is nearly a right angle, with the two adjacent sides measuring $39 \mathrm{~mm}$ and 33 $\mathrm{mm}$. One osteoderm occupies this corner, with its longer axis paralleling the long axis of the fragment. It measures $20 \mathrm{~mm}$ by $10 \mathrm{~mm}$. Two parallel osteoderms compose the remainder of the short axis. The tip of the long axis is formed by a fourth osteoderm, with its edges missing. A prominent 



FIGURE 19. Chinlechelys tenertesta, NMMNH P-16697-4, mesoplastra in 1, external view; 2, external view line drawing; 3, internal view; 4, dorsal side of carapace fragment; and 5, plastron fragment. Short dashes indicate sutures and longer dashes indicate sulci and raised surface structures. 
ridge parallels the long axis on one side. The far edge from the corner of the short axis curves toward the side opposite to this ridge. The long axis of the fragment has a thickened edge toward the presumed lateral side. Furthermore, there is a longitudinal sulcus, possibly outlining the ventral margin of one of the inframarginal scutes.

\section{Hypoplastron (P-16697-14) Figure 20}

The hypoplaston described and illustrated by Joyce et al. (2009, figures $1 \mathrm{i}, 2 \mathrm{i}$ ) is relatively short and broad, including the inguinal notch. The bone measures $118 \mathrm{~mm}$ wide and $50 \mathrm{~mm}$ long. On the dorsal side, about $11 \mathrm{~mm}$ left of the medial edge there is a raised portion inferred to be a suture to the pelvis, measuring $1.7 \mathrm{~mm}$ long and $8 \mathrm{~mm}$ wide. Unlike Joyce et al. (2009), we find a longitudinal sulcus $24 \mathrm{~mm}$ posterior to the anterior most edge of this fragment, curving slightly anteriorly toward the medial edge of the fragment. We identify this sulcus as the abdominal femoral sulcus. It sharply curves around the inguinal notch, outlining a strongly posterior-pointed inguinal scute. The distal margins of this scute are unclear, as no other sulci are visible on the fragment. At just over $9 \mathrm{~mm}$ thick, the shell reaches its greatest observed thickness just medial to the inguinal notch and the bridge.

\section{Plastron fragment (P-16697-4) Figure 19.5}

A small portion of the plastron of indeterminate placement was recently discovered. This fragment is identified as coming from the plastron because of its relatively thick profile and the nature of its sulci, consisting of a prominent raised lip on one side only seen in plastron fragments. Parallel to this sulcus and $\sim 5 \mathrm{~mm}$ anterior is a suture that repeats a recurring pattern in Chinlechelys tenertesta in which lateral sulci parallel a suture.

\section{Left axillary notch (P-16697-17) Figure 18.4}

A small, well-preserved fragment of the left axillary notch is preserved. This shows a distinct surface texture on the ventral side, which continues to a sulcus along the free margin of the fragment. A lateral sulcus is present $\sim 10 \mathrm{~mm}$ medial to the free margin of the fragment.

\section{Carapace and Plastron Fragments Figure 19.4 (P-16697-4)}

Two fragments of the shell were found sandwiched around a piece of matrix. The one inter- preted as dorsal (Figure 19.4) is a highly fractured piece of the carapace that includes a shallow transverse ridge near its posterior edge. The orientation of this fragment is inferred based on the thicker side of the sulcus being anterior in other plastron fragments. The lower fragment, likely from the plastron, shows no clear sutures but has a surface sculpture similar to that seen on the visceral surface of more definitive plastron fragments and is thus inferred to be from the plastron. The placement on the shell of both of these fragments is unclear.

\section{Holotype innominate (P-16697-11) Figure 21.1-2}

The left innominate of Chinlechelys tenertesta was collected at the type locality and inadvertently catalogued as a separate specimen, so Joyce et al. (2009) did not recognize it as part of the holotype. This part of the pelvis and the referred specimen discussed below are recognized as turtle based on their close resemblance to the pelvises of other known turtles. Only the area surrounding the acetabulum is preserved, and this compares most closely with extant Apalone and Chelydra, rather than the Triassic turtles Proganochelys quenstedti, Palaeochersis, and Proterochersis.

The thyroid fenestra appears to be open rather than enclosed in the pubis and ischium. The acetabulum is round, with three raised points, one on each of the pelvic bones. The pubis is crushed ventrally, relative to the ilium and ischium, resulting in some distortion. The dorsal process of the ilium has a near circular cross section offset slightly posteriorly from the highest point of the acetabulum. On the medial surface of the base of the dorsal iliac process there is a shallow concavity, as seen in some turtles. The posterior ischial process has a roughly triangular base, with the ventral side slightly concave. The pubis preserves a broad articulation with the anterior process, covering nearly the full lateral extent of the innominate. The ventral margins of the pubis and ischium are concave, forming the dorsal margin of the thyroid fenestra, the entire pubic portion of which is bordered by the base of the anterior process of the pubis. The sutures of the pubis are unclear.

\section{Referred innominate (P-16621, NMMNH locality 166) \\ Figure 21.3-4}

The left innominate of a turtle was found about $1 \mathrm{~km}$ from the type locality of Chinlechelys tenertesta in the same stratigraphic interval. This innomi- 

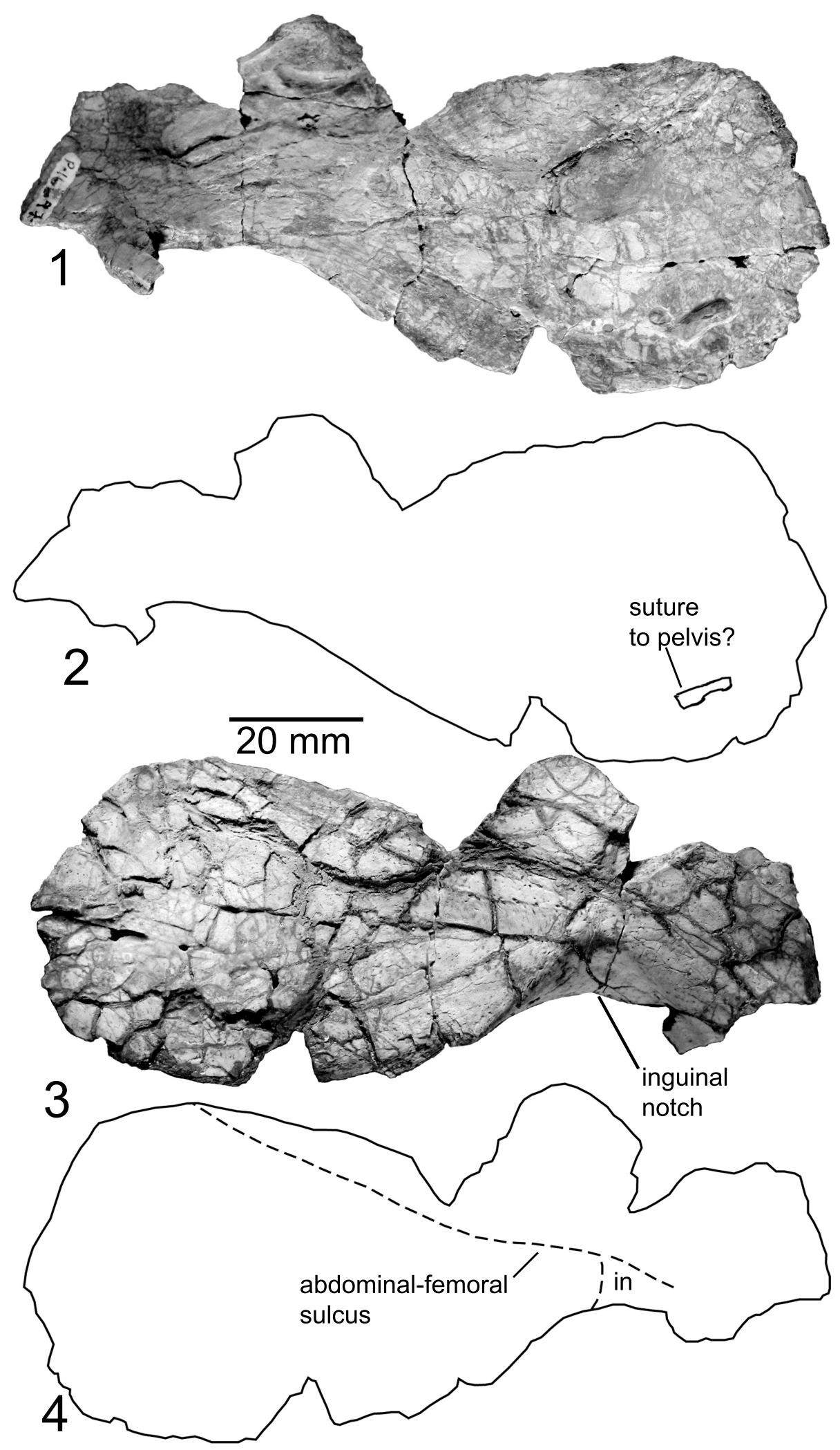

FIGURE 20. Chinlechelys tenertesta, NMMNH P-16697-14, Hypoplastron in dorsal (1) and ventral (3) views. Line drawings of dorsal view (2) and ventral views (4). Note the suture to the pelvis in the lower right of the dorsal view and the longitudinal sulcus crossing the hypoplastron in the ventral view near the edge of the bone. Abbreviation: in, inguinal scute. 


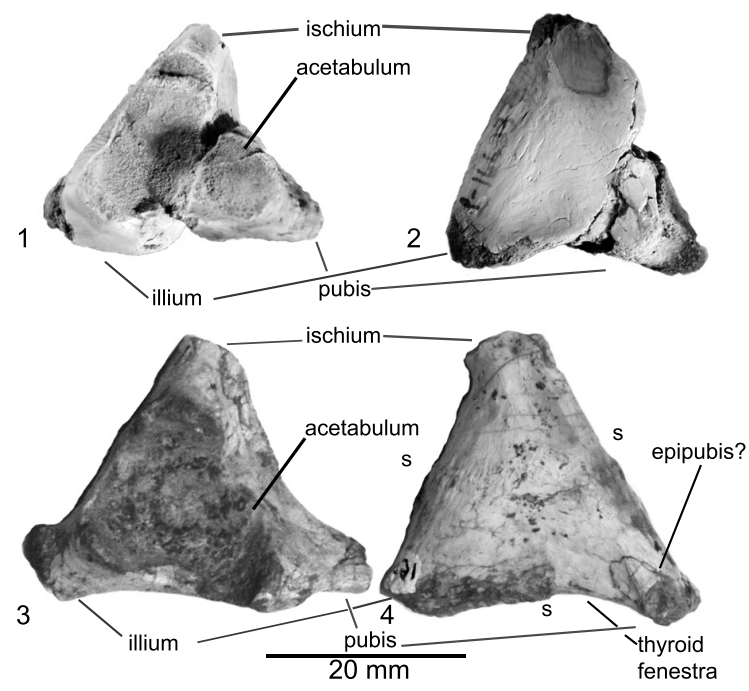

FIGURE 21. Chinlechelys tenertesta innominates: 1. Holotype innominate (P-16697-11) in distal view. 2. Proximal view. 3. Referred innominate (P-16621) distal view. 4. proximal view. Sutures are marked at the free edges of the innominate with a "s."

nate is referred to Chinlechelys tenertesta based on its being identical to the holotype innominate other than its slightly larger size and the absence of crushing. The innominate clearly shows all three major pelvic bones as well as fragments of a possible epipubis at the anterior end. The acetabulum is circular as in the holotype (character 214). The total fragment measures $31 \mathrm{~mm}$ long and $29 \mathrm{~mm}$ high. The bone is divided approximately into thirds, with a triple junction of the sutures on the opposite side from the center of the acetabulum as in the holotype.

\section{Referred Femur (P-4315, NMMNH locality 53) Figure 22}

The head of a left femur is from a locality a few kilometers from the Chinlechelys tenertesta type locality, and in the same stratigraphic interval, so it is tentatively referred to Chinlechelys tenertesta as there are no other turtles known from these strata. It is identified as a turtle because of its enlarged trochanters and deep intertrochanteric fossa. It shows a broad intertrochanteric fossa and a head offset toward the greater trochanter. The head is $16 \mathrm{~mm}$ deep and $14 \mathrm{~mm}$ wide, with $24 \mathrm{~mm}$ of length preserved. The trochanters are separated by $\sim 7 \mathrm{~mm}$ at the proximal end, and the fossa is $\sim 4.5 \mathrm{~mm}$ deep. Towards the center of the head the fossa is deeper than at the external surface of the bone.

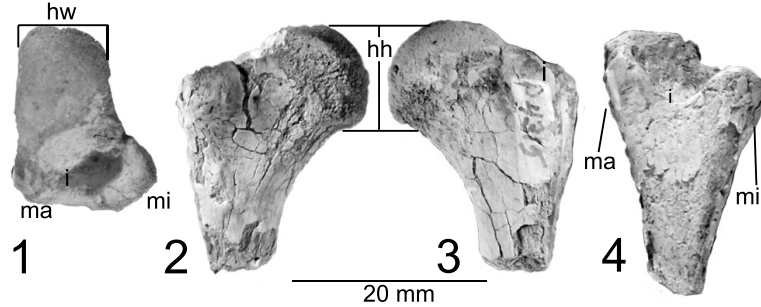

FIGURE 22. Chinlechelys tenertesta, NMMNH P- 4315, referred femoral head: in dorsal (1), posterior (2), anterior (3) and lateral views (4). Abbreviations: hh, head height; hw, head width; i, intertrochanteric fossa; ma, trochanter major; and mi, trochanter minor.

\section{DISCUSSION}

\section{Introduction}

The morphology of Chinlechelys tenertesta leads to several interesting conclusions about the ancestry of turtles and the validity of proposed turtle ancestors. Chinlechelys tenertesta is clearly a turtle, as it possesses several characters unique to Testudinata, including: the intercentra placement of thoracic ribs, the centra fused to a large dorsal plate, and the presence of a hypoplastron. The separation of the ribs and costals in Chinlechelys tenertesta does not support the broadened rib or osteoderm-free hypothesis of shell formation. In this hypothesis, a basal turtle such as Chinlechelys tenertesta would be expected to have broad ribs with no separation of the costal plate from the rib.

We suggest that the taxa most recently suggested to be stem turtles, Eunotosaurus and Pappochelys rosinae, are better understood as members of the Caseidae and Placodontidae, respectively (see below). Current evidence suggests that turtles originated among the Procolophonomorpha. Within this group, we consider the Pareiasauridae the most likely to include the sister taxon of turtles.

Analysis of the phylogenetic position of Chinlechelys tenertesta (Figure 23) was conducted based on the matrix of Szczygielski (2017), which is a revised version of the matrix of Schoch and Sues (2015). Our analysis treated characters as ordered clines. This resulted in a tree length of 1222 with only one topology for the portion of the cladogram nearest turtles. The variation in the most parsimonious trees being confined to the "nycteroleters" and basal eureptiles. Furthermore, Pappochelys rosinae was recovered at the base of the Sauropterygia near the split with Squamata. The analysis recovered Chinlechelys tenertesta as sister to a clade composed of Odontochelys semit- 


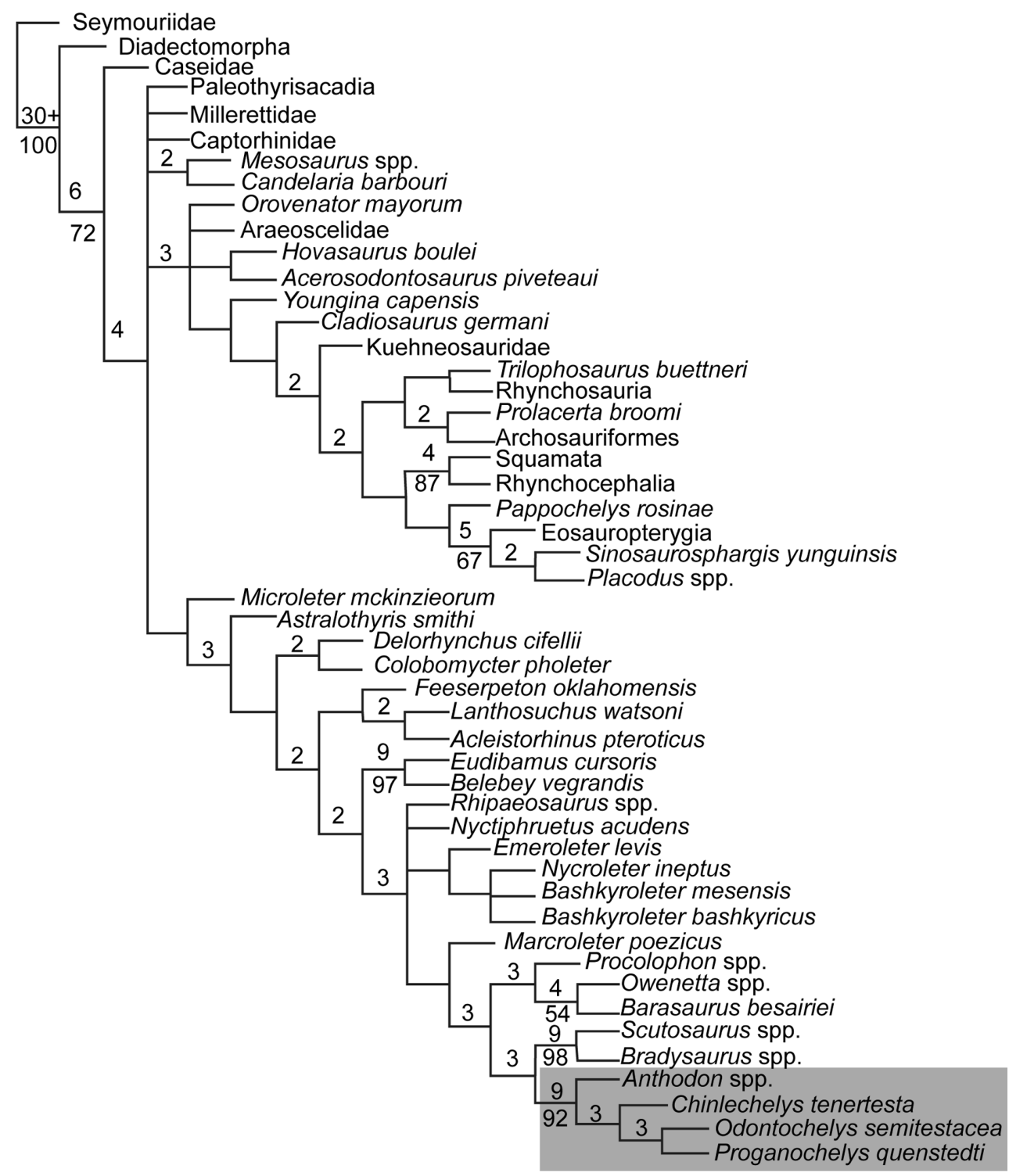

FIGURE 23. Final phylogeny resulting from our cladistic analysis excluding Eunotosaurus, and testing the position of Testudines within the Reptilia. This was based on the modified version of the Szczygielski matrix presented in this paper and run through the program TNT with multistate characters ordered. Bremer support values above one are listed above nodes, and bootstrap values above $50 \%$ are listed below nodes.

estacea and Proganochelys quenstedti. This supports the hypothesis of Joyce et al. (2009) that Chinlechelys tenertesta is the most basal of all known turtles.

\section{Significance of Chinlechelys tenertesta}

The costal bones of turtles have been hypothesized to have one of two origins: either the broadening and fusion of ribs, supported by the proponents of Eunotosaurus and Pappochelys rosinae as ancestral turtles (e.g., Bever et al., 2015; Schoch and Sues, 2015); or the fusion of ribs with overlying osteoderms, which has been linked to a variety of reptiles (e.g., Lee, 1997). The latter hypothesis has been applied to the suggestion of sister group relationships of turtles with placodonts, lepidosaurs, archosaurs, pareiasaurs, and procolophonids. Joyce et al. (2009), in describing Chinlechelys tenertesta, stated that it confirms unequivocally the hypothesis of the fusion of the ribs with the overlying osteoderms. We endorse this conclusion, and further point out that recent developmental studies provide additional support for this view (Rice et al., 2015).

Chinlechelys tenertesta thus provides a solid answer to the long running debate over the origin 
of the turtle carapace. The presence of separate costal and rib bones (Figures 13.3-5, 14.1-2) unequivocally supports the composite model of costal origins. This separation is clear in Chinlechelys tenertesta, including the separation of the anterior and posterior edges of the ribs from the costals (Figure 14), the separation of the two by a suture bordered on both sides by compact bone, and the non-parallel occurrence of costals and ribs with an offset of $\sim 45^{\circ}$ (Figure 13.3). The composite model has been long suggested to favor the parareptile affinities of turtles (Gauthier et al., 1988; Lee, 1997; Lyson et al., 2013b). We consider this consistent with the model of costal formation in early ontogeny presented by Rice et al. (2015). They specifically point out the presence of "islands of bone" beyond the rib periosteum, which we consider a likely remnant of the osteoderm-forming processes that would be expected to be incorporated in shell formation in the osteoderm-bearing hypothesis of shell origins. In Eunotosaurus only the periosteum of the rib is broadened; no surrounding dermis is incorporated, as in turtles. We think that Lyson et al. (2013b), Bever et al. (2015), and Schoch and Sues $(2015,2018)$ have used these developmental data to exclude the possibility of an osteoderm-bearing ancestral turtle in error. The developmental model at present can be interpreted to support either major hypothesis of the origin of costal bones.

Further, this explains the stated uniform histology of the costals and the undisputedly dermal peripheral bones of turtles (Scheyer, 2007). If both costals and peripherals began as separate ossifications (e.g., osteoderms), and one, the costal, merged with an underlying element of the axial skeleton (rib), a certain amount of common morphology in the two elements would be expected. In addition, this agrees with the stated model of costal formation proposed in Rice et al. (2015), as a further development of the similar earlier proposals by Gilbert et al. (2001) and Cebra-Thomas et al. (2005), by which the costals form in two distinct phases. Specifically, the two phases coincide with the onset of normal rib growth and the onset of osteoderm growth. This explains the appearance of centers of ossification outside of the periosteum of the rib (Rice et al., 2015) in the two-phase model. As such, the rib would serve as a central portion of and organizing center for the remainder of the costal rather than as its sole source.

The composite model as the means of costal formation is thus strongly supported by Chinlechelys tenertesta. The general conclusion of Rice et al.
(2015) is that the signals put out from the rib initiate the ossification of the costal plate. We suggest that this organizing role in costal formation is actually a more derived state of turtle evolution based on the separation and nonparallel nature of the costal bones with the ribs in Chinlechelys tenertesta. In more primitive turtles like Chinlechelys tenertesta, the overlying osteoderms are present but they do not seem to be organized by the rib, as in extant turtles.

Peripheral and pygal bones have been identified as dermal ossifications unique to turtles (Delfino et al., 2010). This is supported by their formation late in ontogeny, and their loss in many species retaining all other shell bones (e.g., trionychids and Dermochelys). Despite this, they have a histology identical to other bones of the shell, suggesting a common mechanism in their formation. As such, the common histology of the costals and peripherals is evidence that the two share a common origin as separate ossifications rather than as osteoderms forming the peripherals and broadened ribs forming the costals. These fit the pattern of Proganochelys quenstedti, which has twice the number of peripherals relative to more recent turtles in the parts where the sutures are visible. Chinlechelys tenertesta clearly had more centers of ossification for these bones that were likely fused in later turtles.

Scheyer (2007) pointed out that the processes that form turtle bone do not appear homologous with those in either placodonts or pareiasaurs. However, two modifications to his list of pareiasaur osteoderm characters differentiating them from turtle carapace bones should be noted: ornamental bosses do in fact appear to be present on the carapace bones of the basal turtle Chinlechelys tenertesta, and fragments of the carapace of the fossil dermochelyd turtle Psephophorus do in fact show a radial sculpture (Albright et al., 2003), as in pareiasaurs and their relatives. Further, Scheyer (2007), in analyzing the osteoderms of dermochelyds, found them lacking fusion with the underlying endoskeleton. We believe this indicates that Dermochelys and the fossil dermochelyd Psephophorus (Albright et al., 2003) possessed neotenic morphology that likely provides insight into the ancestral state of turtle shell dermal bone. While Psephophorus is an advanced turtle, the same could be said of Dermochelys, which the original statement was based on. This area of discussion is entirely reliant on the idea that the neonate morphology of dermochelyids is similar to a less derived state of turtle morphology. This interpreta- 
tion fits with the separation and increased number of osteoderms observed in Chinlechelys tenertesta.

\section{COMMENTS ON OTHER EARLY TURTLES AND THEIR PUTATIVE RELATIVES}

\section{Proganochelys quenstedti}

The stem turtle Proganochelys quenstedti from the Upper Triassic (Norian) of Germany was the first Triassic turtle described and remains the most completely known Triassic turtle (Gaffney, 1990). Proganochelys quenstedti has been referred to as the sister-group (the sister-group of the clade that includes all geologically more recent turtles) to all other turtles (e.g., Gaffney, 1990). It is unique relative to all other turtles in its heavily ossified armor on its neck and tail.

\section{Proterochersis}

Proterochersis is a turtle from the Upper Triassic (Norian) of Germany and Poland. Its type specimen was found several meters stratigraphically below that of Proganochelys quenstedti (Fraas, 1913). The revision of Proterochersis by Szczygielski and Sulej $(2016,2019)$ concludes that it is the earliest diverging, fully shelled turtle.

\section{Odontochelys semitestacea}

Odontochelys semitestacea was discovered in Late Triassic (Carnian) marine deposits in China (Li et al., 2008). This proto-turtle is unique in several ways, including the apparent lack of a carapace, peg-like maxillary teeth, mid-centra placement of the ribs and the lack of an osseous connection between the pelvis and the spine ( $\mathrm{Li}$ et al., 2009). Beyond this we argue that in fact no costals are present in Odontochelys semitestacea specimens described by Li (2008) just a broadened rib. This is based on the lack of evidence of any dermal bone formation as opposed to just the normal axial rib bone as seen in any other reptile. Furthermore, we agree with the suggestion of Reisz and Head (2008) that Odontochelys semitestacea is actually a derived aquatic morph rather than the ancestral morphology of all other turtles. The derived position of Odontochelys semitestacea relative to Chinlechelys in our phylogeny fits this hypothesis more closely than the lack of an ossified carapace being the ancestral state of all Testudines.

An important possibility is that Odontochelys semitestacea is a turtle like Dermochelys that evolved to lack a solid shell fused to the ribs. Fur- thermore, the loosely attached nature of the costals in Chinlechelys tenertesta hints at an important and little considered possibility-with no solid attachment the preservational loss of any osteoderms from the carapace of Odontochelys semitestacea would have been very easy. The possibility of missing material thus argues against the use of the lack of a carapace in Odontochelys semitestacea to dismiss osteoderm-bearing ancestors, as was done by $\mathrm{Li}$ et al. (2008), Lyson et al. (2011, 2013b, 2015), and Joyce (2015).

\section{Pappochelys rosinae}

Pappochelys rosinae from the Middle Triassic (Ladinian) of Germany was recently put forward as a proto-turtle by Schoch and Sues $(2015,2018)$ based on seven characters: 142 , intertrochanteric fossa well defined; 164 , unguals at least $50 \%$ longer than penultimate phalanges; 180 , dorsal ribs nearly straight; 181 , dorsal ribs ending smoothly and tapered, indicating loss of ventral ribs or sternum; 187, gastralia incorporated into bony plastron; and 196, dorsal process of maxilla tall with pointed apex. Further, with the publication of a more detailed osteology of Pappochelys rosinae by Schoch and Sues (2018), many of the missing data in the matrix of Szczygielski (2017), which was based on Schoch and Sues (2015), could be coded, reflecting the increased information. These changes are detailed in the appendices and are based on the descriptions and figures of Schoch and Sues (2018). With these new additions, Pappochelys rosinae and turtles are not recovered as closely related, as turtles move into the Parareptilia, while Pappochelys rosinae remains a basal sauropterygian (Figure 23).

Of these characters, 142 are plesiomorphic for the Amniota and thus provides no clear evidence of relationships within this group. Character 164 is an adaptive trait that occurs in a variety of aquatic tetrapods (e.g., Placodus and Alligator). We question that character 180 is coded correctly in the matrix of Schoch and Sues (2015), as the rib shown in their figure 3 curves approximately $63^{\circ}$ from the base of the thickened portion to the distal end of the bone. Character 181 is a trait shared with members of the Pareiasauridae. Furthermore, character 187 is an assumed trait of turtles, not a trait demonstrated by direct observation. Finally, character 196 is problematic, as this pointed apex is not present in basal turtles.

Because of these problems with character scoring, we question the identification of Pappochelys rosinae as a stem turtle. We also note that 
the presence of all of the traits listed above would be expected of a basal placodont, as they are present in the placodonts Pararcus, Placochelys placodontia, and/or Palatodonta (Neenan et al., 2012). This is not surprising, as the next closest relatives of Pappochelys rosinae in the analysis of Schoch and Sues (2015) are placodonts and other sauropterygians. In particular, we suggest that Pappochelys rosinae represents a basal placodont similar to those described by Scheyer et al. (2013). These placodonts, particularly Pararcus (Klein and Scheyer, 2014) and Placodus (Jiang et al., 2008), possess broadened ribs similar to those of Pappochelys rosinae and Palatodonta bleekeri (Neenan et al., 2012), which possess a skull closely resembling that of Pappochelys rosinae, including the presence of similar maxillary teeth and the pointed dorsal projection of the maxilla used to link it with Proganochelys quenstedti (Schoch and Sues, 2015). Furthermore, Pappochelys rosinae possesses a single row of large palatal teeth, as does Palatodonta (Schoch and Sues, 2017). This is unlike Proganochelys quenstedti and Odontochelys, which both have multiple rows of small palatal teeth. While these unusual features might be apomorphic, lacking other conflicting data, these features being similar to other sauropterygians, should be treated as a synapomorphy. Pappochelys rosinae additionally shares the following synapomorphies with placodonts: an elongate, L-shaped jugal, an open lower temporal fossa, and an enlarged suborbital fenestra (Neenan et al., 2012). This L-shaped jugal is a modification of the basal triradiate jugal in which the posterior process is shortened and less prominent, while still technically having three points.

Schoch and Sues (2015) suggested that there are fewer than nine trunk vertebrae in Pappochelys rosinae. However, all specimens are stated to be incomplete and disarticulated, so they do not preserve the entire trunk. Because of the similarities to placodonts, which have about 20 trunk vertebrae, it is logical to assume there was a larger number than nine vertebrae in Pappochelys rosinae. Furthermore, the gastralia reconstruction of Schoch and Sues (2015) is speculative, given that no undisturbed gastralia are preserved. The arrangement of these gastralia was used as a synapomorphy linking Pappochelys rosinae to turtles, despite its uncertainty. We conclude that Pappochelys rosinae is a sauropterygian, likely a basal placodont, and not a basal turtle based on our phylogenetic analysis and comparative anatomy.
Schoch et al. (2019) very recently provided a more detailed assessment of the histology of Pappochelys rosinae. They conclude it is difficult to interpret in terms of paleoecology but generally supports a fossorial or semi-aquatic habitus. Perhaps their most interesting result was that the structure of the medullary cavity and surrounding bone of Pappochelys rosinae is unlike most other amniotes, instead forming in a manner similar to "some placodonts, pistosaurs, and a few large nothosaurs" (p. 2). We suggest this is not a convergent acquisition but rather additional evidence linking Pappochelys rosinae to the placodonts and other early sauropterygians. In light of this interpretation Pappochelys rosinae is an important animal for entirely different reasons than stated by Schoch et al. (2019). It is the most direct evidence of a freshwater stage in the evolution of the sauropterygians as they evolved into a secondarily aquatic habitus. Furthermore, we consider the lack of any sort of plate formation in the gastralia of Pappochelys rosinae further evidence of the distinctiveness of its gastralia from the plastral plates of turtles. Finally, as stated by Schoch et al. (2019), the interpretation of the vertebrae of Pappochelys rosinae in terms of paleoecology is difficult, and, given the other evidence available, we consider a semiaquatic to aquatic lifestyle probable.

\section{Eunotosaurus africanus}

The middle Permian Eunotosaurus africanus has long been of controversial phylogenetic placement. Recent studies by Lyson et al. (2010, 2013a, 2016) and Bever et al. (2015) suggest that Eunotosaurus africanus is a basal pantestudinate. This is based on 15 characters, including: 18, lacrimal duct enclosed by lacrimal;19, skull proportions (postorbital region longer than preorbital region); 42, quadratojugal configuration: vertical dimension exceeding horizontal one by factor of at least two; 48, parietal shelf for adductor musculature absent; 50 , upper temporal fossa present and smaller than orbit; 61, paroccipital process heavy; 114, clavicles broad; 127, ectepicondylar groove completely enclosed forming a foramen without a groove; 170 , T-shaped ribs present, or ribs distinctly T-shaped in cross-section and comprise an endochondral rib portion and a metaplastically ossified dermal portion; 172, number of dorsal vertebrae 10 or fewer; 175 , sacral rib distal overlap small or absent with wide gaps between ribs; 177, number of dorsal ribs 10 or fewer; 178, distinctly broadened ribs present; 179 , dermal bone growing out of perichondral col- 
lar; and 190, number of ventral dermal ossifications (not including pectoral girdle elements) 10 or fewer.

Of these character states, 18, 48, and 114 from the Schoch and Sues (2015) analysis are plesiomorphic for the Amniota and thus of no value for ascertaining the relationships of Eunotosaurus africanus within the amniotes. Character 19 is shared by Eunotosaurus africanus and pareiasaurs and does not link either to turtles. Character 50 is not shared with any definite turtles and is thus entirely dependent on the assignment of Pappochelys rosinae to the turtle stem for its validity. The remaining characters are a mix of relatively common traits among the Amniota and traits based on assumed homologies such as the gastralia of Eunotosaurus africanus and the hyoplastron, hypoplastron and xiphiplastron of turtles.

Based on the presence of an additional fenestra in the skull of a juvenile specimen of Eunotosaurus africanus, Bever et al. (2015) argue that it is a diapsid. This opening, present only in a single juvenile specimen, in our view is better explained as a fontanelle, a common feature of some juvenile mammals and synapsids. We note that the expansion of the supratemporal to fill this gap in the juvenile skull results in a supratemporal with nearly identical morphology to Ennatosaurus (Maddin et al., 2008). We note that a juvenile skull of the eupelycosaur Heleosaurus scholtzi (Botha-Brink and Modesto, 2009, figure 1) approximately $4 \mathrm{~cm}$ long has a depression in the skull at the same location as the supposed fenestra in the skull of the 2 $\mathrm{cm}$ long Eunotosaurus skull. This would fit with the previous interpretation (Lee, 1997) that Eunotosaurus africanus is a synapsid.

In their review of the Triassic European turtles Proterochersis and "Murrhardtia" Szczygielski and Sulej (2016) point out that the short thoracic section of Eunotosaurus africanus is problematic for the hypothesis of the Eunotosaurus africanus ancestry of turtles. This is because it would call for the addition of three thoracic vertebrae from Eunotosaurus africanus to Eorhynchochelys sinensis, and the subsequent loss of two of these vertebrae - one in Proterochersis spp. and then the second in Proganochelys quenstedti.

Lee (1994) stated that five of six caseid synapomorphies from the analyses of Langston (1965) and Reisz (1986) are present in Eunotosaurus africanus, including: (1) overhanging pointed rostrum formed by premaxilla; (2) posterior spur of the supratemporal projects beyond the squamosal; (3) tooth row lies medial to the rest of the maxilla; (4) external naris elongated anteroposteriorly; and (5) maxilla enters ventral margin of the orbit. Lee (1994) went on to point out that Eunotosaurus possesses 10 synapomorphies of caseids identified by Romer and Price (1940), Olson (1968), and Reisz (1986), including: (1) external naris greatly enlarged; (2) orbits located anteriorly, resulting in short facial region; (3) small cranium; (4) ribs project dorsolaterally above the level of the transverse process before curving ventrally; (5) plane of the head and lateral arms of the interclavicle oriented vertically; (6) pineal foramen located anteriorly, near frontal-parietal suture; (7) squamosal reduced to narrow vertical bar; (8) dorsal vertebrae with elongated centra; (9) very broad rib cage; and (10) ilium tall and narrow, sacral blade without long posterior process. Of these, character state 9 (very broad ribcage) was used to link turtles and Eunotosaurus africanus, but is demonstrated by its presence in caseids, aetosaurs and other taxa to have a wider distribution than previously stated (Lyson et al., 2010). Moreover, Eunotosaurus africanus has never been subjected to a thorough phylogenetic analysis, in which all possibilities were included in the analysis. Put another way, all phylogenetic analyses of Eunotosaurus africanus have assumed it to be a parareptile and thus had too small an ingroup, which strongly constrained its position. In every phylogeny it has been assumed to be a reptile, and a generalized synapsid or caseid has been the outgroup rather than a broader sample of caseid morphological diversity (Modesto, 2000; Lyson et al. 2013b; Bever et al., 2015). For example, the generalized caseid of Lyson et al. (2013b) is scored differently than Eunotosaurus africanus for character 82 (mandibular joint: even with occiput (0), behind occiput (1), or anterior to occiput (2)), but the caseids Cotylorhynchus romeri and Casea rutena have the same morphology as Eunotosaurus (Stovall et al., 1996).

More circumstantially, both Eunotosaurus africanus and Casea are interpreted to have been fossorial, and as Lyson et al. (2016) point out, many of the unusual features of Eunotosaurus africanus are distinctly adapted toward this behavior. Furthermore, the transitions necessary to evolve from the early Permian Casea to the middle Permian Eunotosaurus africanus are logically consistent with increased adaptations to fossoriality (Lyson et al., 2016). Indeed, these features are convergent between Eunotosaurus africanus and the extant turtle Gopherus, including an increased area for neck muscle attachment. Any animal using its head for bracing to prevent movement while digging would need an increase in the musculature and 
strength of the neck. The enlargement of the acromion process seen in Eunotosaurus africanus again would be expected of a synapsid adapted to the greater muscle strains involved in fossorial behavior. Further, the argument that this is in some way related to the origin of the tri-radiate scapula of turtles misses that the acromion is found in synapsids and bears little resemblance to that described for Proganochelys quenstedti or Odontochelys. In fact, in the published images of Eunotosaurus africanus (Gow, 1997, figure 10B-D) and the caseid Cotylorhynchus (Stovall et al., 1996, figure 7), the scapulae are quite similar. In short, many of the morphological similarities that have been used to link turtles and Eunotosaurus are entirely adaptive in nature and thus easily reached through convergence.

Also of note is the broad temporal gap between Eunotosaurus africanus ( 261 Ma) and turtle body $(\sim 237 \mathrm{Ma})$ or trace fossils $(\sim 248 \mathrm{Ma})$. In the case of body fossils this is a $\sim 24$ million year gap, and for the trace fossils this is a $\sim 13$ million year gap (Lichtig et al., 2018). There are no known or suggested intermediaries to fill this gap. Conversely, the gap between the youngest pareiasaurs $(\sim 252 \mathrm{Ma})$ and the oldest turtle body fossils is $\sim 15$ million years, and the gap between these pareiasaurs and turtle trace fossils is only $\sim 4$ million years. Given the extensive Permian-Triassic fossil record of tetrapods of the Beaufort Group (e.g., Smith et al., 2012), where the fossils of Eunotosaurus africanus and many of the pareiasaurs hypothesized to be close to the origin of turtles have been collected, it is unlikely that a descendant of an animal as distinctive as Eunotosaurus africanus would have been missed. While the possibility of a ghost range is always present, we suggest this probability is inversely proportional to the size of the inferred ghost range. Put another way, the longer the inferred ghost range, the less likely this is a true ghost range rather than an error in the phylogeny.

As Lyson et al. (2016) correctly point out, all of the features seen in Odontochelys semitestacea and Eunotosaurus africanus inferred to be relevant to digging are also features correlated with forelimb powered swimming. Furthermore, the spine of Odontochelys semitestacea is not reinforced, as is that of Eunotosaurus africanus. Specifically, the pelvis and spine of Odontochelys semitestacea are not sutured together, so they would be ill suited to extensive terrestrial locomotion or burrowing ( $\mathrm{Li}$ et al., 2009). Beyond this, the narrowing of the ribs of Odontochelys semitestacea relative to Eunotosaurus africanus would deprive them of the support function suggested by Lyson et al. (2016). In particular, the mid-centra placement of the rib articulation would give less rigidity to the spine than in any extant turtle, which would seem to fit well with a marine habitus in Odontochelys semitestacea. The lengthened terminal phalanges versus the penultimate phalanges of Odontochelys semitestacea appear to provide no convincing functional distinction between fossorial behavior and forelimb powered swimming, as any lengthening of the hand results in an enlargement of the paddle and thus an advantage in aquatic locomotion. Furthermore, the possession of terminal phalanges longer than penultimate phalanges is widely distributed within the aquatic turtles (e.g., Podocnemis expansa: Gaffney, 1990 and Trachemys scripta: personal observation), thus calling into question its utility as an indicator of fossoriality.

It is also worth noting that a certain degree of digging ability is to be expected of all turtles, based on their need to construct a nest for reproduction (Carr, 1952). We also note that ecology is a poor choice of character for ancestral relationships, as extant and geologically young turtles (e.g., PlioPleistocene) suggest this can be quite variable on a short time scale (Stephens and Wiens, 2003). It is further worth noting that pareiasaurs have the same morphology of short penultimate phalanges and longer terminal phalanges as does Odontochelys semitestacea (Lee, 1994).

\section{PHYLOGENETIC ANALYSES}

The character matrix of Lyson et al. (2013b) and the revised version in Schoch and Sues (2015) were created with the express purpose of exploring the phylogenetic placement of turtles, Eunotosaurus africanus, and Pappochelys rosinae. We also include other previously proposed turtle ancestors, namely the pareiasaur Anthodon spp. coded based on $A$. serrarius and $A$. pricei, the closest relative of turtles according to Lee (1997). This taxon was added as the taxa analyzed previously are not advanced pareiasaur taxa (sensu Lee, 1997). Bradysaurus is generally thought to be a basal pareiasaur, and Scutosaurus a more derived taxon, with Anthodon suggested to be the most derived genus of pareiasaur (Lee, 1997; Tsuji, 2013). Furthermore, Bradysaurus and Scutosaurus are left unchanged from previous phylogenies, so their coding is identical to what has been published previously in Szczygielski (2017). The phylogeny resulting from this is shown in Figure 24.

Furthermore, in preparing our manuscript and matrix, we carefully treated Anthodon spp. and 


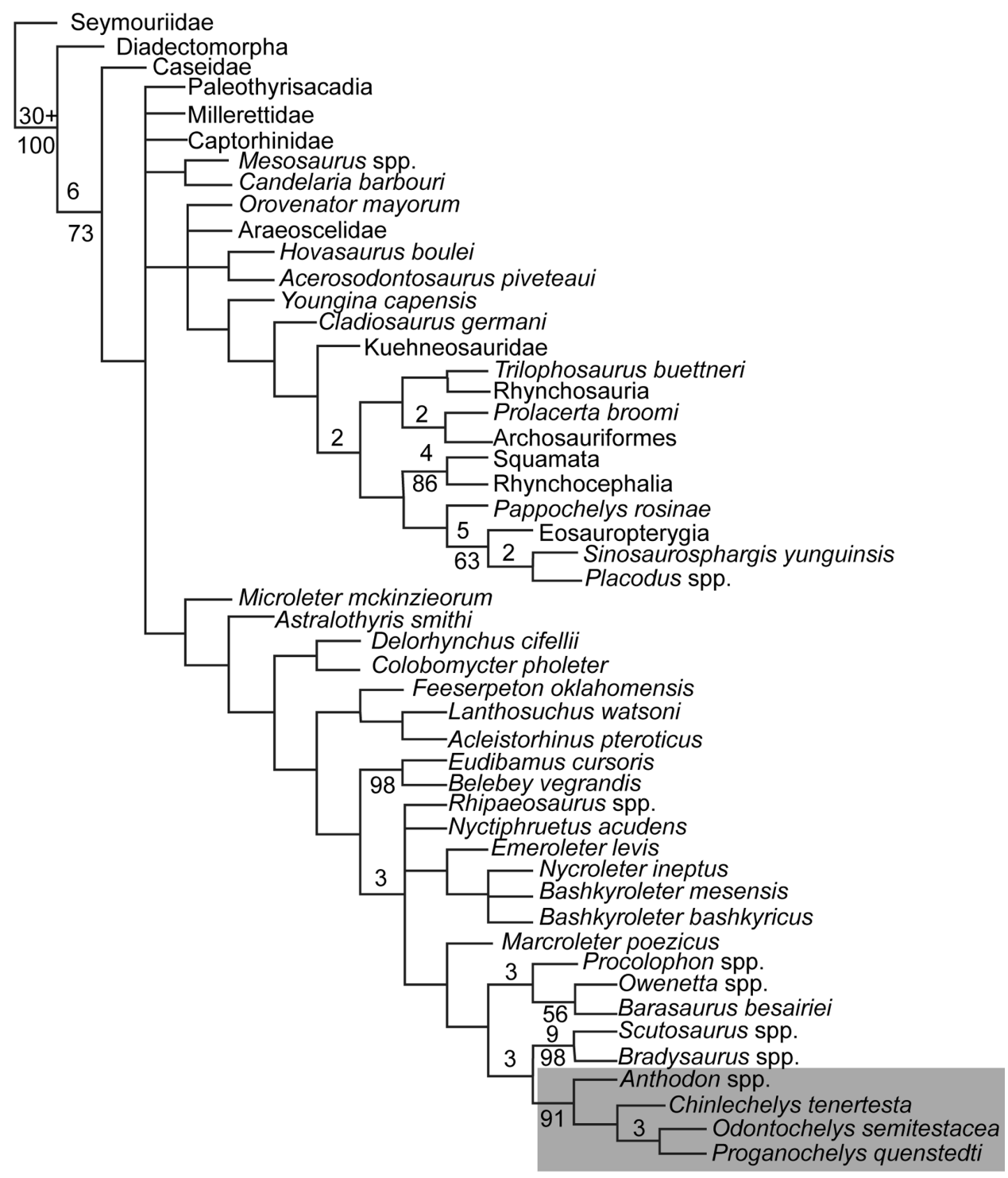

FIGURE 24. Phylogeny resulting from our cladistic analysis, excluding Eunotosaurus, adding in the two autapomorphies of the Pareiasauridae and testing the position of Testudines within the Reptilia. This was based on the modified version of the Szczygielski matrix presented in this paper and run through the program TNT with multistate characters ordered. Bremer support values above one are listed above nodes, and bootstrap values above $50 \%$ are listed below nodes.

Proganochelys quenstedti and ultimately recoded approximately $6 \%$ of the character states. Furthermore, given the suggested caseid affinities of Eunotosaurus africanus, the use of a generalized caseid morphotype in the analysis was ill advised. For example, the placement of the articulation of the jaw in Eunotosaurus africanus is similar to that of Casea rutena (Lee, 1994), but this is not reflected in the generalized caseid coded in the matrices of Lyson et al. (2013b) and Schoch and Sues (2015). Beyond this, the characters used were often not inclusive of all present morpho- types, which consequently were miscoded. The analyses of Lyson et al. (2013b) and the revised version in Schoch and Sues (2015) have many issues particularly with the coding of characters of pareiasaurs. Thus, for example, we examined the coding of two genera, Anthodon and Proganochelys, in detail, finding that on average $6 \%$ of the character coding was problematic (see Appendix 1). We did not review the character scoring of all taxa in detail, but this sample suggests that more issues will be found in a more thorough review. 


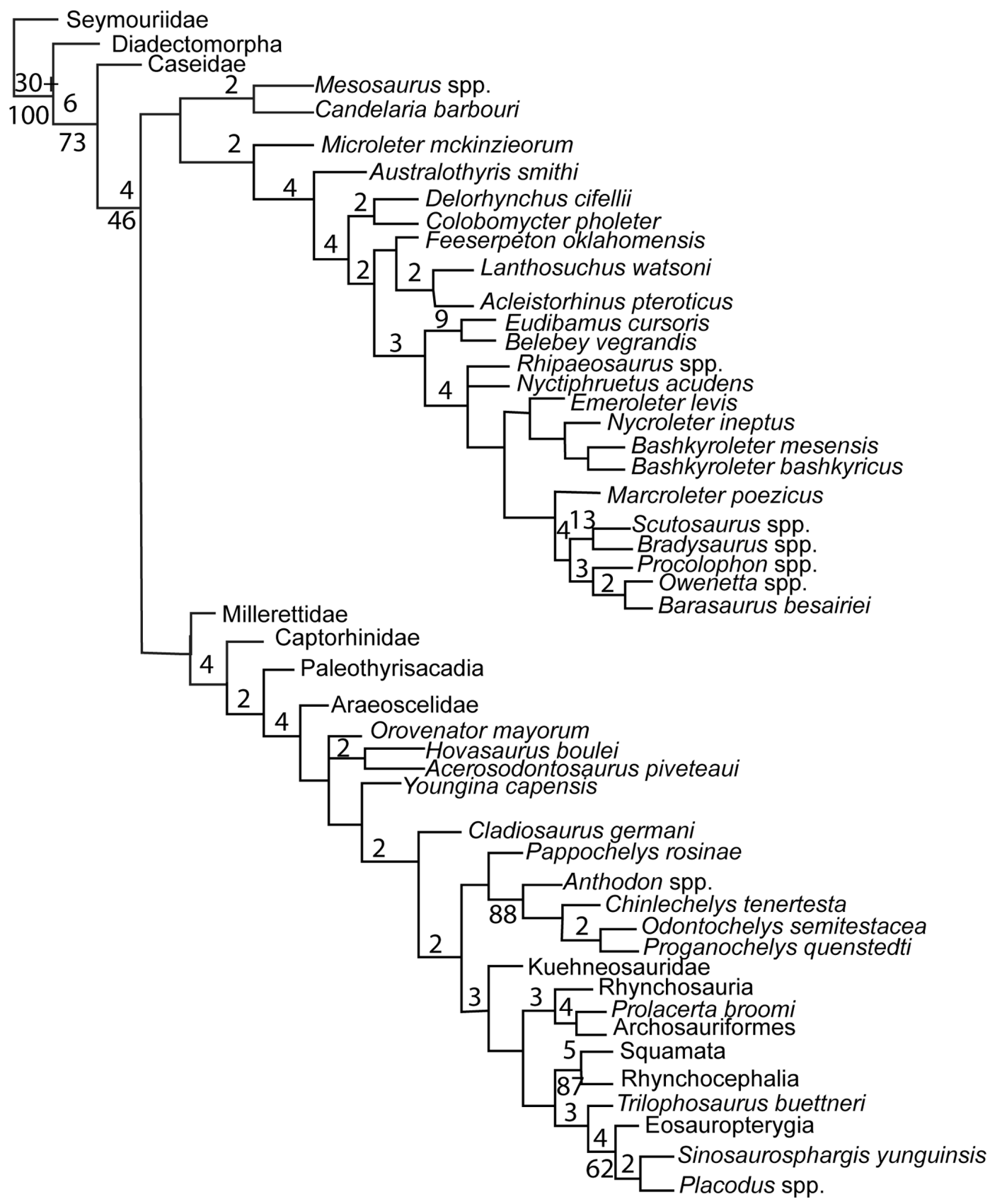

FIGURE 25. Phylogeny resulting from our cladistic analysis, excluding Eunotosaurus as well as all Chinlechelys skull characters, adding in the two autapomorphies of the Pareiasauridae and testing the position of Testudines within the Reptilia. This was based on the modified version of the Szczygielski matrix presented in this paper and run through the program TNT with multistate characters ordered. Bremer support values above one are listed above nodes and bootstrap values above $50 \%$ are listed below nodes.

Hill (2005) performed a cladistic analysis of the amniotes, including many integumentary characters and even behavioral characters. He concluded that 14 synapomorphies support the conclusion that turtles are the sister clade to lepidosaurs. Among these, at least seven are a return to the plesiomorphic state of Reptilia. As an additional check we ran the analysis with the skull characters for Chinlechelys tenertesta removed. This resulted in the movement of Pappochelys rosinae to the sister group to turtles and Anthodon spp. with low support shown in Figure 25. 


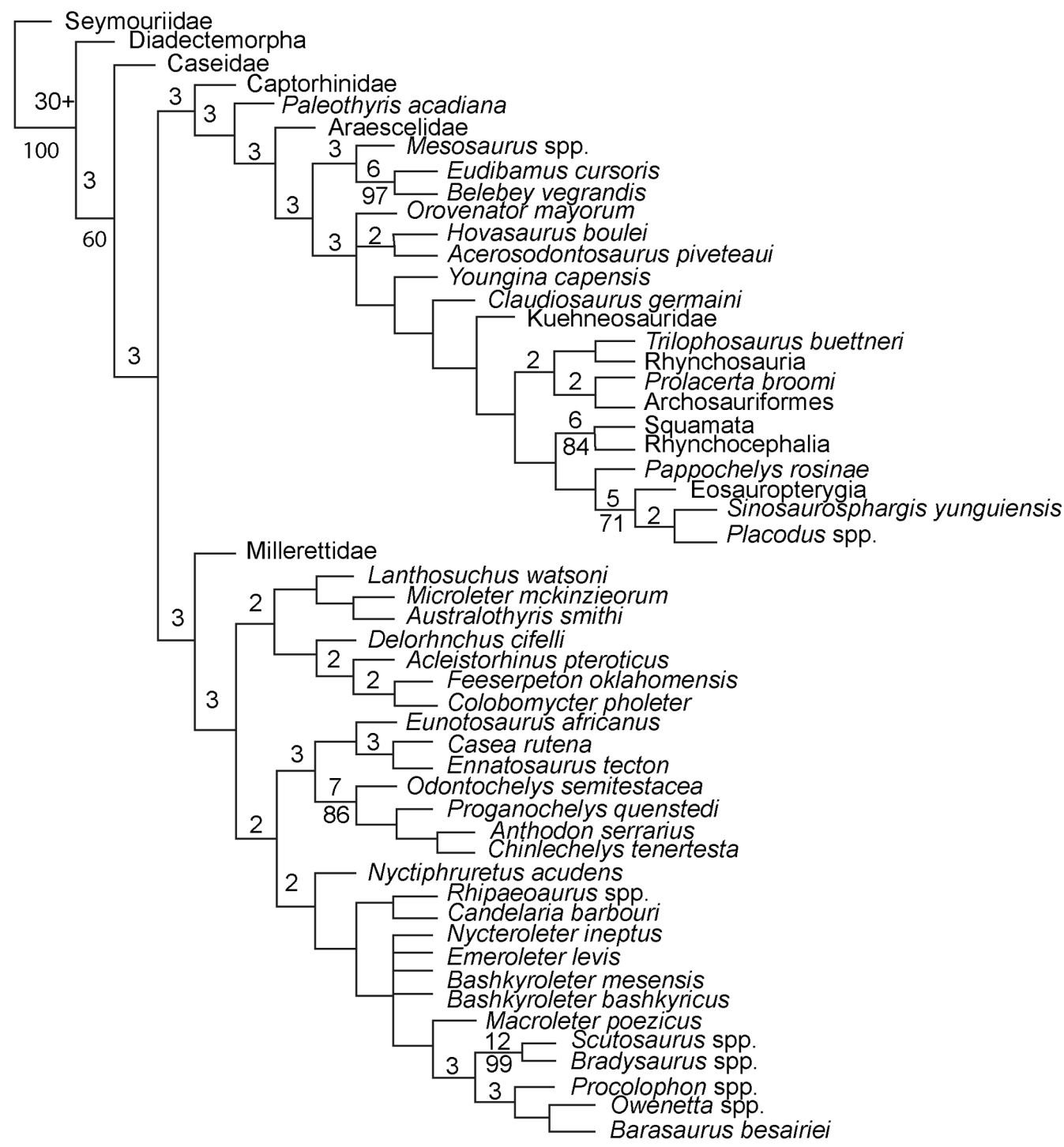

FIGURE 26. Phylogeny resulting from our initial analysis with Eunotosaurus and two caseids included. Bremer support values above one are listed above nodes and bootstrap values above $50 \%$ are listed below nodes.

\section{Analysis of the Effectiveness of Szczygielski (2017) Matrix in Identifying Caseids}

To test our contention that Eunotosaurus is a caseid synapsid, we revised the matrix of Szczygielski (2017) to correct some errors in the coding of Eunotosaurus africanus and additionally coded two uncontroversial caseid synapsids, Casea rutena, and Ennatosaurus tecton, for this matrix. If caseids were correctly dealt with by this matrix they should group with the generalized caseid used as part of the matrix outgroup. The matrix was then run in TNT for 1000 Wagner trees with all multistate characters ordered followed by a TBR sequence saving 100 trees per replication. In addition, we created a matrix with just Eunotosaurus africanus added to the taxa in Figure 23, and then forced Eunotosaurus africanus to be sister to the Caseidae.

This resulted in four equally parsimonious trees with a length of 1309 steps. This result is shown in Figure 26. Eunotosaurus africanus, Casea, and Ennatosaurus form a clade as sister group to the pan-testudines. In addition, the pantestudines include Anthodon as one of its derived members. Other than this the arrangement within the pan-testudines is reversed as far as derived and basal taxa relative to the result without Eunotosaurus africanus and the two caseids. As in all of our analyses, we found Pappochelys rosinae to be the sister group to the Sauropterygia. As an additional test we added only Eunotosaurus africanus 

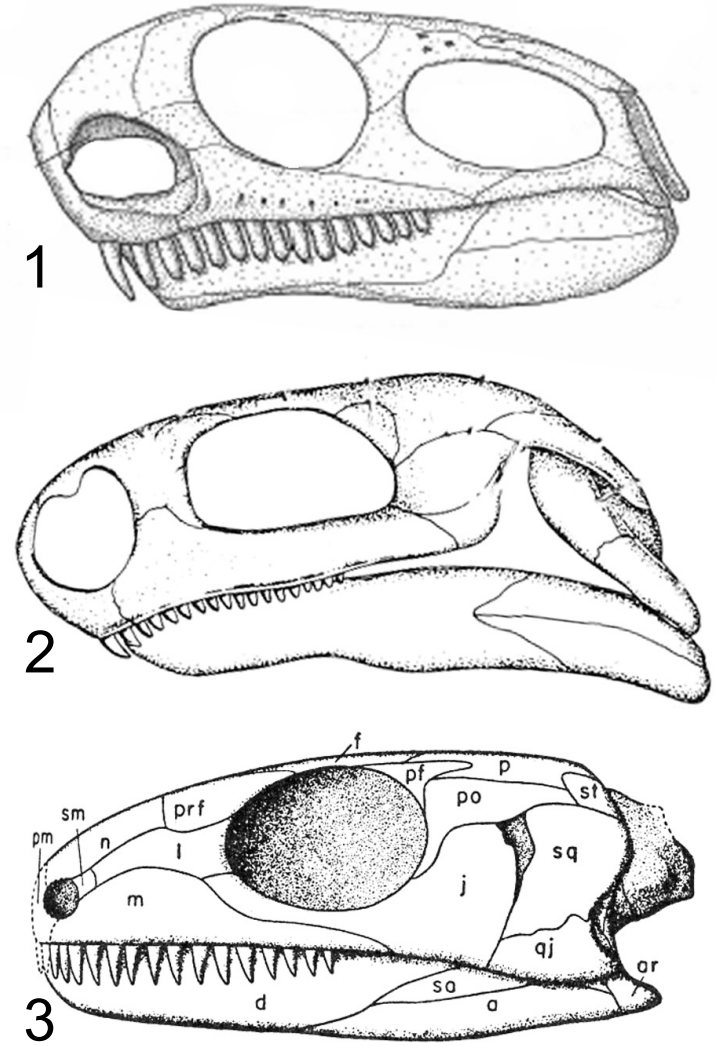

FIGURE 27. Side-by-side comparison of left lateral views of the skulls of: 1. Casea. 2. Eunotosaurus. 3. Milleretta. Not to scale. Casea based on Lee (1993), Eunotosaurus based on Keysler and Gow (1981), and Milleretta based on Romer (1956).

to the analysis in Figure 23 and forced it as the sister to the Caseidae. This analysis resulted in an arrangement similar to that of Figure 23 by majority rule consensus, but almost all clades collapsed in a strict consensus. In addition, we ran the matrix with the two caseids added and Eunotosaurus removed and found the same topology minus Eunotosaurus. This strongly suggests that caseids placed in this reptile matrix behave in a way unexpected by the creators of the original matrix.

This is perhaps less surprising than one might think given the recent publications on Eunotosaurus africanus (Lyson et al., 2010, 2013b; Bever et al. 2015). When looking at a bone map (diagram of bones and sutures) of Eunotosaurus africanus next to Casea and Milleretta, the taxon it has been most frequently linked with in past analyses, the similarities in skull form of Casea and Eunotosaurus africanus are more clear (Figure 27) than looking at these skulls in isolation. To our knowledge this is the first time that Eunotosaurus africanus has been cladistically compared with an individual caseid species, all previous analyses using either a generalized caseid or a generalized synapsid. This again emphasizes the need to avoid untested a priori assumptions, as the assumption that Eunotosaurus africanus is a parareptile was fundamental to its phylogenetic misplacement. As a result of this analysis we chose to exclude Eunotosaurus africanus from our final analysis of testudines phylogenetic position and run a second analysis testing the position of Eunotosaurus africanus within the Synapsida.

\section{Analysis of the position of Eunotosaurus africanus within the Synapsida}

To test our contention that Eunotosaurus africanus is a basal caseasaur, we encoded it into the synapsid matrix of Benson (2012). This matrix was chosen as it was specifically constructed with the intent to test the relationships of basal synapsids and the organization of the major contained clades relative to one another. We undertook analysis using TNT, including 1000 random addition sequences saving 100 trees per replication followed by a sectorial search and three rounds of tree fusing the calculation of a strict consensus of the resulting most parsimonious trees. This resulted in 167 most parsimonious trees of 743 steps, all placing Eunotosaurus africanus at the base of the Caseasauria as sister to all other caseasaurs (Figure 28). At .395 rather than .4508 , this has a slightly lower consistency index $(\mathrm{Cl})$ than Benson's (2012) full data and similarly has a reduced Retention Index (RI) of .698 rather than .795. The rescaled consistency index (RC) is .275 compared to Benson's (2012) original .3396. Conversely, overall higher resolution is seen in the tree, including the placement of Archaeothyris florensis at the base of the Ophiacodontidae without removing Echinerpeton intermedium. Echinerpeton was found to be the sister to a clade formed by both the Caseasauria and the edaphosaur/sphenacodontin clade. In other respects, our phylogeny is identical to that of Benson (2012).

The consistency of Eunotosaurus africanus being placed at the base of the Caseasauria runs counter to most phylogenies, where its placement is labile, moving from tree to tree within the most parsimonious trees. This placement was supported by the characters: 1 , small skull size; 2 , snout proportions; 25 , the ascending process of the maxilla; 56 , frontal length; 65 , postorbital-squamosal contact; 72 , jugal length and the extension of the ante- 


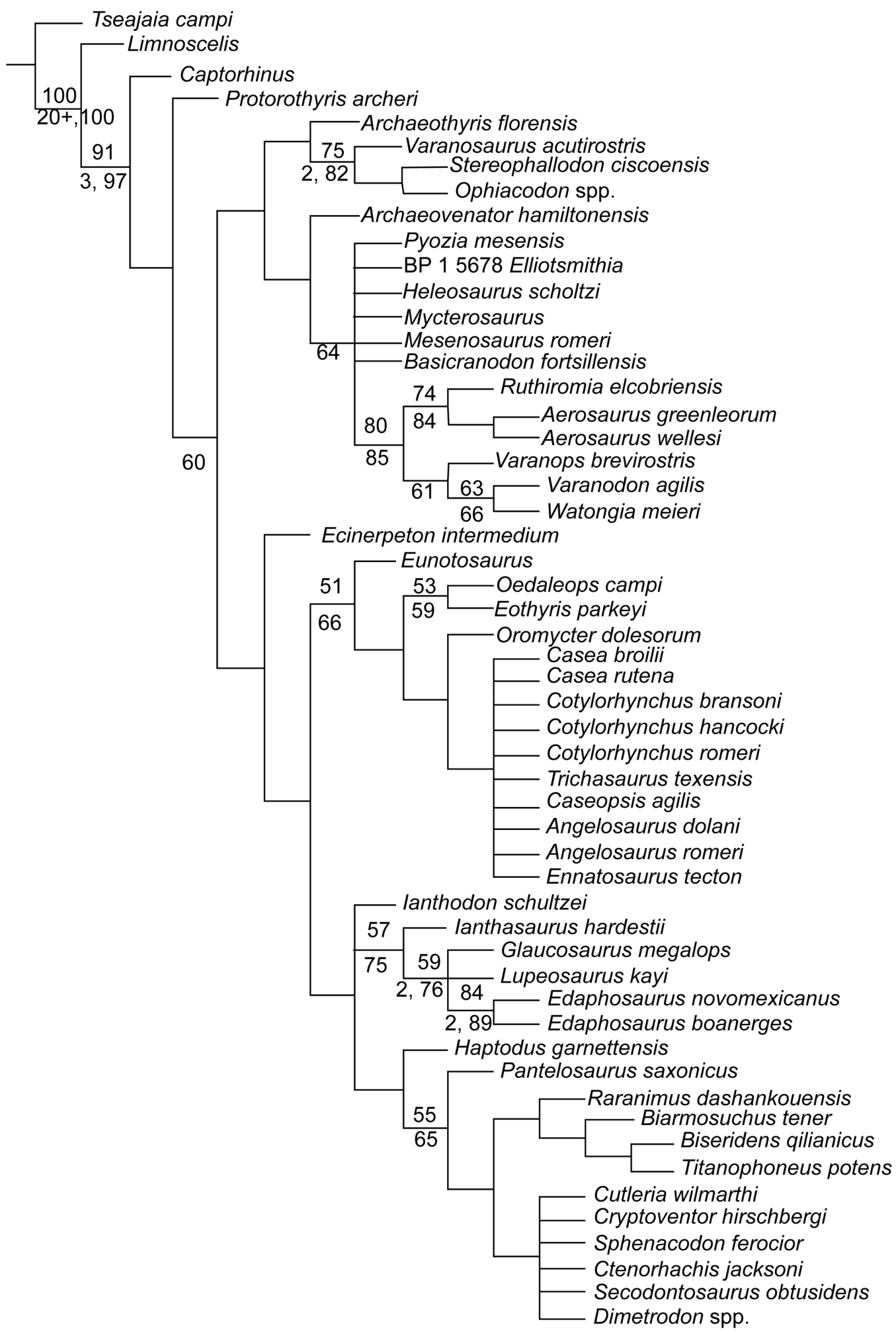

FIGURE 28. Phylogeny resulting from our cladistic analysis of Eunotosaurus using the matrix of Benson (2012) with no taxa pruned to assess the possible position of Eunotosaurus within the Synapsida. Bremer support values above one, followed by Jacknife values over $50 \%$ are listed below the nodes, and bootstrap values above $50 \%$ are listed above nodes. 
rior ramus; 73, jugal anteroposterior thickness of the dorsal ramus; 86 , the morphology of the tabular; 88, supratemporal shape; 96, paraoccipital process morphology; 153, the length of the cervical centra; 170, dorsal rib curvature; and 189, the angle of the head of the interclavicle. These characters scattered throughout the body confidently link Eunotosaurus africanus and the Caseasauria.

\section{Our Analysis of the Position of Testudines}

In addition, we reviewed the phylogeny of Szczygielski (2017), which is based on the phylogeny of Bever et al. (2015), with a few additions. This phylogeny was chosen as it is the most recent update of this matrix that does not conflict with its supporting data. We were not able to use the phylogeny of Schoch and Sues (2018), as the scorings in their published matrix and those of their list of synapomorphies conflicted in several places. In reviewing Szczygielski (2017), we noticed similar coding issues with Proganochelys, Pappochelys, Odontochelys, and the Caseidae as well as with the archosauromorph Trilophosaurus (cf. Spielmann et al., 2008). Thus, among these taxa, $13 \%$ of Proganochelys, $12 \%$ of Odontochelys, $18 \%$ Pappochelys, and 9\% of the Caseidae characters were miscoded, and $24 \%$ of Trilophosaurus's characters were miscoded (Appendix 2). Furthermore, Anthodon spp. was conspicuously absent in the analysis of Szczygielski (2017), given its inclusion in the previous work on the subject by Lyson et al. (2013b).

Methodology. Anthodon spp. and Chinlechelys tenertesta were coded for the matrix of Szczygielski (2017) and subjected to cladistic analysis (Appendices 3-4 and Figure 23; see Appendix 5 for 3D models further clarifying Chinlechelys tenertesta characters). We additionally made corrections and updates to the matrix for the taxa Odontochelys, Caseidae, and Pappochelys (detailed in the appendices). Eunotosaurus was excluded from the analysis based on the reasons stated above and the lack of sufficient taxonomic coverage in the matrix of Szczygielski (2017) to adequately test its position within the Tetrapoda and the results of our previous analysis. This was analyzed using TNT through a strict consensus of the shortest trees resulting from 10,000 random addition sequences saving 100 trees per replication followed by a sectorial search and three rounds of tree fusing. This was then subjected to standard (sample with replacement) bootstrap analysis based on 1,000 replicates. Following this Bremer analysis was performed including all trees up to 30 steps longer than our consensus tree. This was based on TBR from the consensus tree to find all trees of up to 30 more steps. This analysis was done separately from the bootstrap analysis and did not include the trees used for the bootstrap analysis.

Results. Our new phylogeny has turtles returning to the position of Lee (1997) as the sister taxon to Anthodon (Figure 23). This clade was well supported with a bootstrap value of $92 \%$. Furthermore, Chinlechelys tenertesta was recovered as the sister-group of the clade that includes Proganochelys quenstedti and Odontochelys, supporting our position that Chinlechelys tenertesta is not the sister taxon of Proganochelys quenstedti alone and is the most basal known turtle. In addition, Pappochelys was recovered as the basal-most member of the Sauropterygia in line with our assessment that it is a basal placodont, one of the earliest diverging branches of the Sauropterygia. Candelaria barbouri has been shown in past publications (Szczygielski, 2017) to have an extremely flexible position in phylogenetic analysis, moving extensively, depending on what taxa it is compared with as well as weighting procedures and other changes. This is detailed at length in Szczygielski (2017). We do not place much value on its position in our matrix.

Conclusions. Overall, no higher order relationships in this matrix receive significant support from bootstrap analysis or Bremer supports. Given these results, we conclude that turtles were derived from the dwarf pareiasaurs as suggested by Lee (1997). Furthermore, we conclude that Pappochelys is not closely related to turtles and is a sauropterygian.

As an additional test we created a matrix modified from that of our previous analysis with the addition of two autapomorphies of the Pareiasauridae, including the ventral process of the mandible and the expanded cheek region seen in many pareiasaurs. These were coded as absent $(0)$ in all taxa except for the pareiasaurs, Anthodon, Scutosaurus, and Bradysaurus. This resulted in little change in the resulting phylogeny (Figure 24). This further corroborates the connection between pareiasaurs and turtles.

Finally, given the suggestion that our identification of the skull of Chinlechelys is uncertain, we re-ran the analysis with all of the cranial characters for Chinlechelys coded as ambiguous. This matrix included the two autapomorphies of Pareiasauridae described above. This resulted in a rather confused tree with turtles as eureptiles, with Anthodon as their sister taxon separated from other pareiasaurs (Figure 25). This phylogenetic hypothesis is 
highly unlikely, but does show that Anthodon is very similar to Chinlechelys, even without the skull fragments coded.

\section{MOLECULAR STUDIES}

Crawford et al. (2012) contend that molecular data solidly support a turtle-archosaur sister group relationship. However, no archosaur fossil has been discovered that is considered a strong candidate for an ancestral turtle. The recurring issue of morphological analyses of turtle origins is that nothing in the Archosauria has ever been linked to Testudines based on morphology, but molecular data consistently finds this result. An alternative interpretation is that the long period of time since turtle origins led to convergence and long branch attraction, acting to create the impression of short stems of shared genetic similarities. These small similarities between the ingroup taxa in the analysis of Crawford et al. (2012) and Chiari et al. (2012) indicate that this is an important possibility to consider. There are more data separating turtles from archosaurs than separating this proposed clade from tuataras and squamates (Crawford et al., 2012; Chiari et al., 2012). In addition, this difference is still smaller than that between the compared testudines, squamates, aves, or crocodylians.

Chiari et al. (2012) suggested that turtles form a clade with either crocodylians or archosaurs. This study, like Crawford et al. (2012) and others, places a very short stem on a testudines-archosaur clade, indicating a small amount of inferred shared genetic similarity between these groups, which is dwarfed by the differences between them. Hugall et al. (2007) used the RAG-1 gene alone and came to a similar result, with a short stem connecting archosaurs and turtles, providing limited confidence to their result. Indeed, the strong support of these molecular studies and others was challenged by Lu et al. (2013), who questioned the value of the methods of assessing support due to the possibility of the enormous datasets used with current common statistical methods artificially increasing the statistical support of their results. Lu et al. (2013) concluded that confidence in the turtle-archosaur clade of many molecular phylogenies is overestimated due to systematic biases. They argued that the large number of characters pushes the bootstrap values up artificially. Lu et al. (2013) suggested that these large multi-gene combined analyses and total evidence analysis fail to deal with the genes as they exist. Instead of working on genes as individual units, large combined analyses taking this small part of this and that gene create a false sense of similarity by taking the small pieces of different genes that match and using them to draw connections instead of following how individual genes change through evolution. To counteract this, Lu et al. (2013) developed their genes as characters, comparing each gene and then using those comparisons as the characters for the analysis. They found support for both a lepidosaur-turtle clade and a turtle-sauria clade based on their "genes as characters" methodology with similar levels of support for the archosaur-turtle clade. This was further supported by Lee (2013), who suggested that the molecular data could be argued to support any of the three conclusions to a similar degree. Given this uncertainty from the genetic data alone, we suggest that the turtle-sauria clade favored by morphological and ontogenetic studies is most probable.

Another conclusion of Chiari et al. (2012) is that the divergence of turtles from other living reptiles occurred between 274 and $233 \mathrm{Ma}$. This encompasses many millions of years before fossil turtles are known and is thus consistent with available fossil evidence: the oldest known turtle body fossils at $\sim 237 \mathrm{Ma}$ and the oldest turtle trace fossils are 248 Ma (Rühle von Lilienstern, 1939; Haubold, 1971; Lovelace and Lovelace, 2012; Lichtig et al., 2018). Unfortunately, this only confirms that the part of the fossil record that includes the information we seek has not yet been uncovered. Alternatively, Alfaro et al. (2009) estimated a divergence age of turtles from other reptiles between 245 and $210 \mathrm{Ma}$ (mean $215 \mathrm{Ma}$ ), which is not consistent with the fossil record of the earliest turtles.

\section{ONTOGENY-BASED PHYLOGENETIC HYPOTHESIS}

Another method to infer turtle relationships has been suggested based on ontogeny, specifically the timing of osteogenesis (Werneburg and Sánchez-Villagra, 2009). Werneburg and SánchezVillagra conclude that turtles occupy a position outside Sauria, supporting the classical hypothesis of the anapsid origin of turtles. In addition, Schoch's (2006) analysis of tetrapod ontogeny based on the timing of cranial osteogenesis failed to link turtles solidly to extant reptiles, as would be expected, instead grouping them with the amphibian genus Ascaphus. 


\section{PALEOECOLOGY OF EARLY TURTLES}

The paleoecology of basal turtles has been suggested to offer an additional clue as to their ancestry (Joyce and Gauthier, 2004). However, ecology and closely tied morphology can change rapidly in turtles and is thus unreliable as an indicator of ancestry (Lichtig and Lucas, 2017). Nevertheless, we think it is worth summarizing what we know about the paleoecology of the earliest turtles.

Chinlechelys tenertesta was found in overbank floodplain deposits of the Bull Canyon Formation (Newell, 1993; Lucas et al., 2001). The morphology of Chinlechelys tenertesta gives some clues as to its habitus, including the strong bend to the carapace and the shape of the femoral head. The strong bend in the carapace would likely cause turbulent water flow and make swimming less efficient, and thus suggests a terrestrial or bottom walking habit for this animal. This increased roughness of the carapace's surface is seen in extant, bottom-walking turtles such as Chelus, Chelydra and Macrochelys. The referred femur of Chinlechelys tenertesta has a deep intertrochanteric fossa and a head that is not as elongate as in most swimming turtles. This leads to the conclusion that its shape, combined with the patterns in extant turtle femora noted by Zug (1971), suggests an aquatic turtle frequently moving in a bottom walking motion, as in extant Chelydra.

Much of what makes us think that Chinlechelys tenertesta was an aquatic bottom walker can also be applied to Proganochelys quenstedti, but Joyce and Gauthier (2004) and Scheyer et al. (2007) suggested that Proganochelys quenstedti was a terrestrial turtle based on forelimb morphology and shell bone histology. Contrary to this, Lichtig and Lucas (2017) argued that Proganochelys quenstedti was aquatic based both on shell morphology and femur morphology. This contradiction suggests we still have a lot to learn about the ecology of these early turtles.

Rothschild and Naples (2015) argued against the ecology of Odontochelys semitestacea being terrestrial or shallow water, because of the presence of signs of decompression syndrome in the humerus. This suggests that Odontochelys semitestacea was marine and took part in diving behaviors. They concluded that Odontochelys semitestacea represents a recent immigrant to the aquatic environment, so that its anatomy is not entirely adapted for this habitus. This generally conforms to the hypothesis of Odontochelys semitestacea as a secondarily aquatic branch of the turtle stem, advocated by Reisz and Head (2008). As such it does not provide solid evidence of the later origin of the carapace relative to the plastron.

To conclude, Triassic turtles had already diverged to fit a broad array of environments so that no single characterization is entirely accurate. These animals were not just terrestrial (Joyce and Gauthier, 2004; Scheyer et al., 2007) or aquatic (Li et al., 2008), but rather inhabited most of the environments they do today with the exception of the pelagic environment (Lichtig and Lucas, 2017).

\section{FORELIMB MORPHOLOGY MODELS AND PUTATIVE TURTLE SISTER TAXA}

Another way to look at whether groups are natural is to look if they follow the same patterns in their morphology. Joyce and Gauthier (2004) created a model of turtle forelimb proportions and their relationship to the ecology of the animal. Turtles all have a similar humerus length-to-ulna-length ratio, averaging 1.56 and ranging from 1.29-1.80. All turtles that have been assessed by this method follow this pattern. We examined an additional five taxa, including Eunotosaurus africanus, Edaphosaurus sp., Odontochelys, Pappochelys, and Anthodon. This resulted in humerus-length-to-ulna-length ratios of $0.65,1.11,1.44,1.35$, and 1.66 , respectively. Of these, only Eunotosaurus africanus and Edaphosaurus, an uncontroversial synapsid, fell outside the observed range of turtle morphology. We also calculated the three ratios used in the paleoecology estimation of Joyce and Gauthier (2004), the results of which are shown in Figure 29. Again, only Eunotosaurus africanus and Edaphosaurus fall outside the turtle morphospace. We suggest that this indicates that neither of these species are part of the taxon (e.g., turtles), which fits with Lee's (1993) assertion that Eunotosaurus africanus is a synapsid. This is similar to the result from Foth et al. (2017), which reached the strange conclusion that Eunotosaurus africanus is a marine turtle. Given the known geology of the Karroo, Eunotosaurus africanus could not be a marine organism. We suggest the answer is that comparing a synapsid to turtles would logically not provide accurate results.

\section{TURTLES AS DWARF PAREIASAURS}

We propose that turtles are the descendants of dwarf pareiasaurs as suggested by Lee (1993, 1994, 1997) (Figure 30). We note that the sutures of the neural plates and costal plates in Chinlechelys are oriented relative to the ribs in the same manner, with the ribs at an approximately $45^{\circ}$ 
1

2



FIGURE 29. Plot showing the forelimb proportions of several putative basal turtles and the synapsid Edaphosaurus as a comparison relative to a variety of extant turtles. 1. comparison relative to various turtle taxa; and 2. comparison to different habitats of extant turtles. Figure is based on Joyce and Gauthier (2004).

angle and the sutures coming to an anteriorly facing point on the neurals, as the dermal plates of dwarf pareiasaurs such as Anthodon and Nanopareia (Findlay, 1970). This posteriorly angled, trending posteriorly toward the lateral edge arrangement is not common among dorsal plates in the Amniota. More often, parallel rows perpendicular to the midline are seen, as in Alligator, ankylosaurs and aetosaurs or as a collection of dozens of small plates as in armadillos. Furthermore, Chinlechelys tenert-

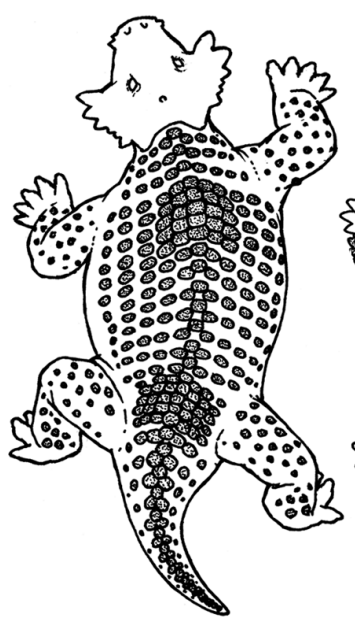

Scutosaurus

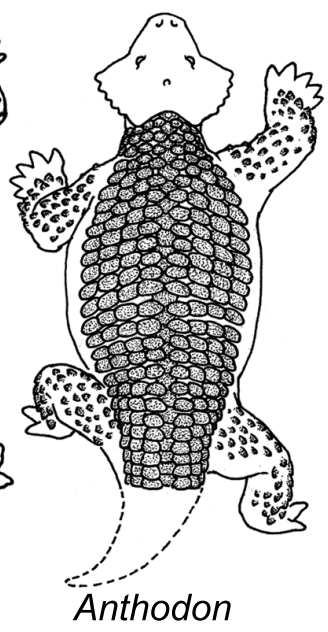

Anthodon

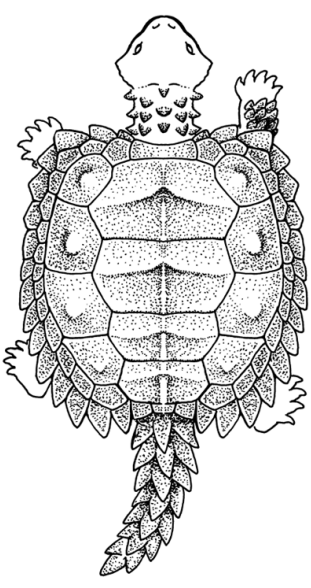

Chinlechelys


Kayentachelys

FIGURE 30. Drawings of proposed origin of turtles from left to right: Scutosaurus, modified from Lee (1997), Anthodon, modified from Lee (1997), Chinlechelys tenertesta, new reconstruction, Proganochelys quenstedti, modified from Joyce et al., (2009), Kayentachelys, modified from Joyce et al., (2009). Drawings by Matt Celeskey. 



FIGURE 31. Otic structures of the Pareiasauridae and Chinlechelys: 1, Embrithosaurus schwarzi skull fragment in ventral view (from Van Den Brant et al., 2019), showing the simple otic notch; 2, Anthodon pricei skull in ventral view (image from Mike S.Y. Lee) showing the conical shape in one dimension of the notch in this pareiasaur, previously hypothesized to be close to Testudines; 3, ventral view of the skull fragment of Chinlechelys showing the cone-shaped (in two dimensions) otic conch.

esta has multiple rows of costals as seen in Anthodon and quite unlike the single row suggested by the broadened rib hypothesis based on Eunotosaurus.

The otic notch of pareiasaurs is different from Proganochelys quenstedti or Odontochelys, in which the otic notch is exposed laterally, but is similar to that seen in the probable Chinlechelys tenertesta skull fragment. This feature is absent in Odontochelys semitestacea and Proganochelys quenstedti, but it is present in Chinlechelys tenertesta, which is clearly a turtle. Even among the Procolophonomorpha and turtles, otic openings are generally laterally placed and thus not equivalent to those seen in Chinlechelys tenertesta and pareiasaurs. Conversely, the ventral placement of the otic notch is shared by Chinlechelys tenertesta and the pareiasaurs (e.g., Anthodon)-this is a very unusual placement for any amniote-we are not aware of any diapsid reptile with a ventrally placed ear-and thus a strong link between the two groups. Furthermore, the dorsal conical processes on the skull in Chinlechelys tenertesta are similar to those on dwarf pareiasaurs, but are not seen in Eunotosaurus or Pappochelys. This process can be seen to form a natural cline of states from the oldest pareiasaurs to Chinlechelys, evolving from a simple notch to a two-dimensional cone shape and then to a three-dimensional cone (Figure 31). Further, the deep temporal emargination of Chinleche- lys tenertesta is similar to pareiasaurs, and more pronounced than in Proganochelys quenstedti and Odontochelys. This temporal emargination is not seen in procolophonids, Eunotosaurus, or Pappochelys. In addition, the trackways of pareiasaurs indicate that they had already developed the unusual dual gait seen in turtles (Lichtig et al., 2018).Finally, and more circumstantially, when turtles are born with a pineal foramen it has been reported as anteriorly displaced (e.g., Gaffney, 1979 , p. 76) rather than centrally placed as in Eunotosaurus (Lyson et al., 2013b). Conversely, this is the normal arrangement for parareptiles (e.g., pareiasaurs) and basal eureptiles such as Captorhinus (Heaton, 1979; Lee, 1994). For these reasons, as well as those previously outlined by Lee (1993, 1994, 1997), we consider pareiasaurs the most likely ancestors or outgroup of turtles.

Pareiasaurs fit a Neodarwinian gradualistic model of turtle origins slowly accruing the traits characterizing turtles over an extended period of time. This model is preferred as opposed to the saltational or rapid model of turtles origins, supported by many recent publications (Lyson et al., 2010, 2011, 2013a, b, 2014; Bever et al. 2015; Schoch and Sues, 2015; Szczygielski, 2017). Pareiasaur morphology includes several features otherwise restricted to turtles or to turtles and eureptiles. Among these are the hooked fifth metatarsal, and the dual gait method of locomotion. The 
dual gait of turtles and pareiasaurs strongly suggests the existence of soft tissue similarities supporting this unusual walking gait. This walking gait allows for locomotion with minimal motion of the spine, a key precursor for the formation of a rigid armored carapace.

Furthermore, the ventilatory apparatus of turtles-highly modified to accommodate the lack of costal motion as in other extant reptiles (Lyson et al., 2014)-would also be required of the heavily armored dwarf pareiasaurs of the genera Anthodon and Nanopareia. This is because the fully sutured carapace present in these animals would not allow costal movement to draw air into the lungs. This is unlike the armor of placodonts, aetosaurs, and other armored reptiles with a more flexible, unfused armor covering that would still have allowed costal motion. The one possible exception to this is the more heavily armored cyamodontoid placodonts, which have partially fused ventral osteoderm mosaics. Conversely, the ventral osteoderm mosaics of cyamodontid placodonts are tightly aligned with the underlying gastralia in regular lines as seen in aetosaur dorsal armor and likely allowed significant motion relative to one another possibly allowing costal breathing (Rieppel, 2002). What we thus propose is largely a return to the "composite" model discussed in Rieppel (2017) in which an increasingly osteoderm-covered animal unites these osteoderms with the underlying ribs to form the carapace (Figure 28). Parallel to this the armor plates of the ventral region undergo serial fusion to form the bones of the plastron.

The extant turtle Dermochelys coriacea differs from all other living turtles in that it lacks the costal bones seen in other extant turtles, and instead has a carapace composed of osteoderms and an underlying, completely separated rib cage (Spotila and Tomillo, 2015). This is similar to the morphology of Chinlechelys tenertesta, in which the ribs are separate ossifications under a layer of costal bones (osteoderms). We hypothesize that the apparent lack of differentiation of the ribs and costals in other extant turtles is a derived state that is reversed in Dermochelys, obscuring the composite origin of what appears to be a single bone in extant turtles. This may simply be the difference between whether the rib enters the dermis during development or remains just ventral to it. The model of carapace formation from osteoderms and ribs is supported by the morphology of Chinlechelys tenertesta and possibly by the carapace of Dermochelys. If our hypothesis is correct, the formation of the carapace in Dermochelys may be the result of the absence of the ontogenetic step of the rib entering the dermis and fusing with the overlying osteoderms as it does in all other turtles. If this is the case it strongly supports the composite model of turtle origins.

\section{CONCLUSIONS}

In conclusion, Chinlechelys tenertesta advances our knowledge of turtle origins and leads us to several significant conclusions:

1. Chinlechelys tenertesta is the most basal turtle known.

2. Chinlechelys tenertesta unambiguously supports the composite model of carapace formation.

3. Chinlechelys tenertesta has a pareiasaur-like skull.

4. Chinlechelys tenertesta has an unusual arrangement of its dorsal osteoderms similar to that of dwarf pareiasaurs.

5. Pappochelys is a basal sauropterygian.

6. Eunotosaurus africanus is an aberrant caseid synapsid.

7. Turtles are derived from dwarf pareiasaurs.

\section{ACKNOWLEDGMENTS}

We thank M. Laurin and an anonymous reviewer for their detailed reviews that improved the clarity and content of our manuscript. We also thank Sandia National Laboratory for providing the ct-scan images used in this paper. Larry Rinehart provided expert preparation, and the collaboration in the field of A. P. Hunt is appreciated. 


\section{REFERENCES}

Albright, L.B. III, Woodburne, M.O., Case, J. A., and Chaney, D.S. 2003. A leatherback sea turtle from the Eocene of Antarctica: Implications for the antiquity of gigantothermy in Dermochelydae. Journal of Vertebrate Paleontology, 23:945-949. https://doi.org/10.1671/1886-19

Alfaro, M.E., Santini, F., Brock, C., Alamillo, H., Dornburg, A., Rabosky, D.L., Carnevale, G., and Harmong, L. 2009. Nine exceptional radiations plus high turnover explain species diversity in jawed vertebrates. PNAS, 106:13410-13414. https://doi.org/10.3410/f.1570993.1061096

Anquetin, J., Barrett, P.M., Jones, M.E.H., Moore-Fay, S., and Evans, S. 2008. A new stem turtle from the Middle Jurassic of Scotland: new insights into the evolution and palaeoecology of basal turtles. Proceedings of the Royal Society B, 276:879-886. https://doi.org/10.1098/rspb.2008.1429

Benson, R.B. 2012. Interrelationships of basal synapsids: cranial and postcranial morphological partitions suggest different topologies. Journal of Systematic Palaeontology, 10:601-624. https://doi.org/10.1080/14772019.2011.631042

Bever, G.S., Lyson, T.R., Field, D.J., and Bhullar, B.S. 2015. Evolutionary origin of the turtle skull. Nature, 525:239-242. https://doi.org/10.1038/nature14900

Botha-Brink, J. and Modesto, S.P. 2009. Anatomy and relationships of the middle Permian varanopid Heleosaurus scholtzi based on a social aggregation from the Karroo Basin of South Africa. Journal of Vertebrate Paleontology, 29:389-400. https://doi.org/10.1671/039.029.0209

Burke, A.C. 1989. Development of the turtle carapace: Implications for the evolution of a novel bauplan. Journal of Morphology, 199:363-378. https://doi.org/10.1002/jmor.1051990310

Carr, A. 1952. Handbook of Turtles: The Turtles of the United States, Canada, and Baja California. Cornell University Press, Ithica, New York.

Carroll, R.L. 2013. Problems of the ancestry of turtles, p. 19-36. In Brinkman, D. B., Holroyd P. A., and Gardner J. D. (eds.), Morphology and Evolution of Turtles. Springer, New York. https://doi.org/10.1007/978-94-007-4309-0_3

Chiari, Y., Cahais, V., Galtier, N., and Delsuc, F. 2012. Phylogenomic analyses support the position of turtles as the sister group of birds and crocodiles (Archosauria). BMC Biology, 10:65. https://doi.org/10.1186/1741-7007-10-65

Clark, J. and Carroll, R.L. 1973. Romeriid reptiles from the lower Permian. Bulletin of the Museum of Comparative Zoology, 144:353-407.

Cope, E.D. 1871. On the homologies of some of the cranial bones of the Reptilia and on the systematic arrangement of the Class. Proceedings of the American Association for the Advancement of Science, 1871:194-247.

Crawford, N.G., Faircloth, B.C., McCormack, J.E., Brumfield, R.T., Winker, K., and Glenn, T.C. 2012. More than 1000 ultraconserved elements provide evidence that turtles are the sister group of archosaurs. Biology Letters, 8:783-786, https://doi.org/10.1098/rsbl.2012.0331

de Broin, F. 1984. Proganochelys ruchae n. sp., chélonien du Trias supérieur de Thaïlande. Studia Palaeocheloniologica, 1:87-97.

Delfino, M., Scheyer, T.M., Fritz, U., and Sánchez-Villagra, M.R. 2010. An integrative approach to examining a homology question: shell structures in soft-shell turtles. Biological Journal of the Linnean Society, 99:462-476. https://doi.org/10.1111/j.1095-8312.2009.01356.x

Epperlein, H-H., Khattak, S., Knapp, D., Tanaka, E.M., and Malashichev, Y.B. 2012. Neural crest does not contribute to the neck and shoulder in the Axolotl (Ambystoma mexicanum). PLOS One, 7, 12: e52244. https://doi.org/10.1371/journal.pone.0052244

Findlay, G.H. 1970. Skin structure of small pareiasaurs. With comments on their taxonomy in the Cistecephalus zone. Palaeontologica Africana, 13:15-23.

Foth, C., Rabi, M., and Joyce, W.G. 2017. Skull shape variation in extant and extinct Testudinata and its relation to habitat and feeding ecology. Acta Zoologica, 98:310-325. https://doi.org/10.1111/azo.12181

Frass, V.E. 1913. Proterochersis, eine Pleurodire Schildkröte aus dem Keuper. Jahreshefte der Gesellschaft für Naturkunde in Württemberg, 69:13-90.

Gaffney, E.S. 1979. Comparative cranial morphology of recent and fossil turtles. Bulletin of the American Museum of Natural History, 164:67-376. 
Gaffney, E.S. 1990. The comparative osteology of the Triassic turtle Proganochelys. Bulletin of the American Museum of Natural History, 194:1-263.

Gardiner, B.G. 1982 Tetrapod classification. Zoological Journal of the Linnean Society, 74:207232. https://doi.org/10.1111/j.1096-3642.1982.tb01148.x

Gauthier, J.A., Kluge, A.G., and Rowe, T. 1988. The early evolution of the Amniota, p. 103-155. In Benton, M.J. (ed.), The Phylogeny and Classification of the Tetrapoda. Clarendon Press, Oxford.

Gilbert, S.F., Loredo, G.A., Brukman, A., and Burke, A.C. 2001. Morphogenesis of the turtle shell: the development of a novel structure in tetrapod evolution. Evolution \& Development, 3:4758. https://doi.org/10.1046/j.1525-142x.2001.003002047.x

Gilbert, S.F., Bender, G., Betters, E., Yin, M., and Cebra-Thomas, J.A. 2007a. The contribution of neural crest cells to the nuchal bone and plastron of the turtle shell. Integrative and Comparative Biology, 47:401-408. https://doi.org/10.1093/icb/icm020

Gilbert, S.F., Cebra-Thomas, J.A., and Burke, A.C. 2007b. How the turtle gets its shell, p. 1-16. In Wyneken, J., Godfrey, M.H., and Bels, V. (eds.), Biology of Turtles, CRC Press, Boca Raton, Florida. https://doi.org/10.1201/9780849333392

Gow, C.E. 1997. A reassessment of Eunotosaurus africanus Seeley (Amniota: Parareptilia). Palaeontologia Africana, 34:33-42.

Gregory, W.K. 1946. Pareiasaurs versus placodonts as near ancestors to the turtles. Bulletin of the American Museum of Natural History, 86:279-326.

Haubold, H. 1971. Die Tetrapodenfährten des Buntsandsteins in der Deutschen Demokratischen Republik und in Westdeutschland und ihre Äquivalente in der gesamten Trias. Paläontologische Abhandlungen A Paläozoologie, 4:395-660.

Hay, O.P. 1905. On the group of fossil turtles known as the Amphichelydia; with remarks on the origins and relationships of the suborders, superfamilies, and families of Testudines. Bulletin of the American Museum of Natural History, 21:137-175.

Hay, O.P. 1921. On the phylogeny of the shell of the Testudinata and the relationships of Dermochelys. Journal of Morphology, 36:421-445.

Heaton, M.J. 1979. Cranial anatomy of primitive captorhinid reptiles from the Late Pennsylvanian and early Permian Oklahoma and Texas. Oklahoma Geological Survey Bulletin, 127:1-84.

Hill, R.V. 2005. Integration of morphological data sets for phylogenetic analysis of Amniota: the importance of integumentary characters and increased taxonomic sampling. Systematic Biology, 54:530-547. https://doi.org/10.1080/10635150590950326

Hugall, A.F., Foster, R., and Lee, M.S.Y. 2007. Calibration choice, rate smoothing, and the pattern of tetrapod diversification according to the long nuclear gene RAG-1. Systematic Biology, 56:543-563. https://doi.org/10.1080/10635150701477825

Hunt, A.P. 2001. The vertebrate fauna, biostratigraphy and biochronology of the type Revueltian land-vertebrate faunachron, Bull Canyon Formation (Upper Triassic), east-central New Mexico. New Mexico Geological Society Guidebook, 52:123-151.

Jenkins, F.A., Shubin, N.H., Amaral, W.W., Gatesy, S.M., Schaff, C.R., Clemmensen, L.B., Downs, W.R., Davidson, A.R., Bonde, N., and Osbæck, F. 1994. Late Triassic continental vertebrates and depositional environments of the Fleming Fjord Formation, Jameson Land, East Greenland. Meddelelser om Greenland Geoscience, 32:1-25.

Jiang, D.Y., Motani, R., Hao, W.C., Rieppel, O., Sun, Y.L., Schmitz, L., and Sun, Z.Y. 2008. First record of Placodontoidea (Reptilia, Sauropterygia, Placodontia) from the eastern Tethys. Journal of Vertebrate Paleontology, 28:904-908. https://doi.org/10.1671/0272-4634(2008)28[904:froprs]2.0.co;2

Joyce W.G. 2015. The origin of turtles: A paleontological perspective. Journal of Experimental Zoology Molecular and Developmental Evolution, 324:181-193. https://doi.org/10.1002/jez.b.22609

Joyce, W.G. 2017. A review of the fossil record of basal Mesozoic turtles. Bulletin of the Peabody Museum of Natural History, 58:65-113. https://doi.org/10.3374/014.058.0105

Joyce, W.G. and Gauthier, J.A. 2004. Palaeoecology of Triassic stem turtles sheds new light on turtle origins. Proceedings of the Royal Society B, 271:1-5. https://doi.org/10.1098/rspb.2003.2523

Joyce, W.G., Parham, J.F., and Gauthier, J.A. 2004. Developing a protocol for the conversion of rank-based taxon names to phylogenetically defined clade names, as exemplified by turtles. Journal of Paleontology, 78:989-1013. https://doi.org/10.1666/0022-3360(2004)078<0989:DAPFTC>2.0.CO;2 
Joyce, W.G., Jenkins, F.A., and Rowe, T.R. 2006. The presence of cleithra in the basal turtle Kayentachelys aprix. Fossil Turtle Research, 1:93-103.

Joyce, W.G., Lucas, S.G., Scheyer, T.M., Heckert, A.B., and Hunt, A.P. 2009. A thin-shelled reptile from the Late Triassic of North America and the origin of the turtle shell. Proceedings of the Royal Society B, 276:507-513. https://doi.org/10.1098/rspb.2008.1196.

Keysey, A.W. and Gow, C.E. 1981. First complete skull of the Permian reptile Eunotosaurus africanus Seeley. South African Journal of Science, 77:417-420.

Klein, N. and Scheyer, T.M. 2014. A new placodont sauropterygian from the Middle Triassic of the Netherlands. Acta Palaeontologica Polonica, 59:887-902. https://doi.org/10.4202/app.2012.0147

Kubo, T. 2010. Extant lizard tracks: Variation and implications for paleoichnology. Ichnos, 17:187196. https://doi.org/10.1080/10420940.2010.502500

Langston, W. 1965. Oedalops campi (Reptilia: Pelycosauria). New genus and species from the lower Permian of New Mexico and the family Eothyrididae. Bulletin of the Texas Memorial Museum, 9:1-46.

Laurin, M. and Reisz, R.R. 1995. A reevaluation of early amniote phylogeny. Zoological Journal of the Linnean Society, 113:165-223. https://doi.org/10.1111/j.1096-3642.1995.tb00932.x

Lee, M.S.Y. 1993. The origin of the turtle body plan: Bridging a famous morphological gap. Science, 261:1716-1720. https://doi.org/10.1126/science.261.5129.1716

Lee, M.S.Y. 1994. Evolutionary Morphology of Pareiasaurs. Unpublished Ph.D. dissertation thesis, Queens' College, University of Cambridge.

Lee, M.S.Y. 1997. Pareiasaur phylogeny and the origin of turtles. Zoological Journal of the Linnean Society, 120:120-280. https://doi.org/10.1111/j.1096-3642.1997.tb01279.x

Lee, M.S.Y. 2000. The Russian pareiasaurs, p. 71-85. In Benton, M.J., Shishkin, M.A., Unwin, D.M., and Kurochkin, E.N. (eds.), The Age of Dinosaurs in Russia and Mongolia. Cambridge University Press, Cambridge.

Lee, M.S.Y. 2013. Turtle origins: insights from phylogenetic retrofitting and molecular scaffolds. Journal of Evolutionary Biology, 26:2729-2738. https://doi.org/10.1111/jeb.12268

Li, C., Wu, X., Rieppel, O., Wang, L., and Zhao, L. 2008. An ancestral turtle from the Late Triassic of southwestern China. Nature, 456:497-501. https://doi.org/10.1038/nature07533

Li, C., Wu, X., and Rieppel, O. 2009. Osteological anatomy of Odontochelys semitestacea from the Late Triassic of China, p. 104-106. In Brinkmann, D.B. (ed.), Turtle Symposium Abstracts. Royal Tyrrell Museum of Paleontology, Drumheller, Canada.

Lichtig, A.J. and Lucas, S.G. 2017. A simple method for inferring habitats of extinct turtles. Palaeoworld 26:581-588. https://doi.org/10.1016/j.palwor.2017.02.001

Lichtig, A.J., Lucas, S.G., Klein, H., and Lovelace, D.M. 2018. Triassic turtle tracks and the origin of turtles: Historical Biology, 30:1112-1122. https://doi.org/10.1080/08912963.2017.1339037

Lovelace, D.M. and Lovelace, S.D. 2012. Paleoenvironments and paleoecology of a Lower Triassic invertebrate and vertebrate ichnoassemblage from the Red Peak Formation (Chugwater Group), central Wyoming. Palaios, 27:636-657. https://doi.org/10.2110/palo.2012.p12-011r

Lu, B., Yang, W., Dai, Q., and Fu, J. 2013. Using genes as characters and a parsimony analysis to explore the phylogenetic position of turtles. PLOS One, 8:e79348. https://doi.org/10.1371/journal.pone.0079348

Lucas, S.G. and Hunt, A.P. 1993. Tetrapod biochronology of the Chinle Group (Upper Triassic), western United States. New Mexico Museum of Natural History and Science Bulletin, 3:327329.

Lucas, S.G., Heckert, A.B., and Hunt, A.P. 2000. Probable turtle from the Upper Triassic of eastcentral New Mexico. Neues Jahrbuch für Geologie und Paläontologie Monatshefte, 5:287300. https://doi.org/10.1127/njgpm/2000/2000/287

Lucas, S.G., Tanner, L.H., Kozur, H.W., Weems, R.E., and Heckert, A.B. 2012. The Late Triassic timescale: Age and correlation of the Carnian-Norian boundary. Earth-Science Reviews, 114:1-18. https://doi.org/10.1016/j.earscirev.2012.04.002

Lyson, T.R. and Joyce, W.G. 2010. A new baenid turtle from the Upper Cretaceous (Maastrichtian) Hell Creek Formation of North Dakota and a preliminary taxonomic review of Cretaceous Baenidae. Journal of Vertebrate Paleontology, 30:394-402. https://doi.org/10.1080/02724631003618389

Lyson, T.R., Bever, G.S., Bhullar, B.S., Joyce, W.G., and Gauthier, J.A. 2010. Transitional fossils and the origin of turtles. Biology Letters, 6: 830-833. https://doi.org/10.1098/rsbl.2010.0371 
Lyson, T.R., Sperling, E.A., Heimberg, A.M., Gauthier, J.A., King, B.L., and Peterson, K.J. 2012. MicroRNAs support a turtle + lizard clade. Biology Letters, 8:104-107. https://doi.org/10.1098/rsbl.2011.0477

Lyson, T.R., Bhullar, B-A, S., Bever, G.S., Joyce, W.G., Queiroz, K., Abzhanov, A., and Gauthier, J.A. 2013a. Homology of the enigmatic nuchal bone reveals novel reorganization of the shoulder girdle in the evolution of the turtle shell. Evolution and Development, 15:317-325. https://doi.org/10.1111/ede.12041

Lyson, T.R., Bever, G.S., Scheyer, T.M., Hsiang, A.Y., and Gauthier, J.A. 2013b. Evolutionary origin of the turtle shell. Current Biology, 23:1113-1119. https://doi.org/10.1016/j.cub.2013.05.003

Lyson, T.R., Schachner, E.R., Botha-Brink, J., Scheyer, T.M., Lambertz, M., Bever, G.S., Rubridge, B.S., and de Queiroz, K. 2014. Origin of the unique ventilatory apparatus of turtles. Nature Communications, 5:5211. https://doi.org/10.1038/ncomms6211

Lyson, T.R., Rubidge, B.S., Scheyer, T.M., de Queiroz, K., Schachner, E.R., Smith, R.M., and Bever, G.S. 2016. Fossorial origin of the turtle shell. Current Biology, 26:1887-1894. https://doi.org/10.1016/j.cub.2016.05.020

Maddin, H.C., Sidor, C.A., and Reisz, R.R. 2008. Cranial anatomy of Ennatosaurus tecton (Synapsida: Caseidae) from the middle Permian of Russia and the evolutionary relationships of the Caseidae. Journal of Vertebrate Paleontology, 28:160-180. https://doi.org/10.1671/0272-4634(2008)28[160:caoets]2.0.co;2

Matsuoka, T., Ahlberg, P.E., Kessaris, N., lannarelli, P., Dennehy, U., Richardson, W.D., McMahon, A.P., and Koentges, G. 2005. Neural crest origins of the neck and shoulder. Nature, 436: 347-355. https://doi.org/10.1038/nature03837

Modesto, S.P. 2000. Eunotosaurus africanus and the Gondwanan ancestry of anapsid reptiles. Palaeontologia Africana, 36:15-20.

Neenan, J.M., Klein, N., and Scheyer, T.M. 2012. European origin of placodont marine reptiles and the evolution of crushing dentition in Placodontia. Nature Communications, 4:1621, https://doi.org/10.1038/ncomms2633

Newell, A.J. 1993. Depositional environment of the Late Triassic Bull Canyon Formation. New Mexico Museum of Natural History and Science Bulletin, 3:359-368.

Olson, E.C. 1968. The family Caseidae. Fieldiana, Geology, 17:223-349.

Reisz, R.R. 1986. Pelycosauria. Encyclopedia of Paleoherpetology 17A, Gustav Fischer Verlag, Stuttgart.

Reisz, R.R. and Head, J.J. 2008. Turtle origins out to sea. Nature, 456:450-451. https://doi.org/10.1038/456450a

Reisz, R.R. and Laurin, M. 1991. Owenetta and the origin of turtles. Nature, 349:324-326. https://doi.org/10.1038/349324a0

Rice, R., Riccio, P., Gilbert, S.F., and Cebra-Thomas, J. 2015. Emerging from the rib: Resolving the turtle controversies. Journal of Experimental Zoology Molecular and Developmental Evolution, 324B:208-220. https://doi.org/10.1002/jez.b.22600

Rieppel, O. 2002. The dermal armor of the cyamodontoid placodonts (Reptilia, Sauropterygia). Fieldiana, Geology new series, 46:1-41. https://doi.org/10.5962/bhl.title.3275

Rieppel, O. 2013. The evolution of the turtle shell, p. 51-61. In Brinkman, D.B., Holroyd P.A., and Gardner J.D. (eds.), Morphology and Evolution of Turtles. Springer, New York.

Rieppel, O. 2017. Turtles as Hopeful Monsters, Origins and Evolution. Indiana University Press, Bloomington.

Rieppel, O. and Reisz, R.R. 1999. The origin and early evolution of turtles. Annual Review of Ecology and Systematics, 30:1-22. https://doi.org/10.1146/annurev.ecolsys.30.1.1

Romer, A.S. 1956. Osteology of the Reptiles. University of Chicago Press, Chicago.

Romer, A.S. and Price, L.I. 1940. Review of the Pelycosauria. Geological Society of America Special Paper, 28:1-538. https://doi.org/10.1130/spe28-p1

Rothschild, B.M. and Naples, V. 2015. Decompression syndrome and diving behavior in Odontochelys, the first turtle. Acta Palaeontologica Polonica, 60:163-167. https://doi.org/10.4202/app.2012.0113

Rühle v. Lilienstern, H. 1939. Fährten und Spüren im Chirotheriem-Sandstein von Südthüringen. Fortschritte der Geologie und Paläontologie, 12:293-387.

Scheyer, T.M. 2007. Comparative Bone Histology of the Turtle Shell (Carapace and Plastron) Implications for Turtle Systematics, Functional Morphology and Turtle Origins. Unpublished Ph.D. dissertation thesis, University of Bonn. 
Scheyer, T.M., Brüllmann, B., and Sánchez-Villagra, M.R. 2008. The ontogeny of the shell in side-necked turtles, with emphasis on the homologies of costal and neural bones. Journal of Morphology, 269:1008-1021. https://doi.org/10.1002/jmor.10637

Scheyer, T.M., Werneburg, I., Mitgutsch, C., Delfino, M., and Sánchez-Villagra, M.R. 2013. Three ways to tackle the turtle: Integrating fossils, comparative embryology, and microanatomy, $p$. 63-70. In Brinkman, D.B., Holroyd P.A., and Gardner J.D., (eds.). Morphology and Evolution of Turtles. Springer, New York. https://doi.org/10.1007/978-94-007-4309-0_6

Schoch, R.R. 2006. Skull ontogeny: developmental patterns of fishes conserved across major tetrapod clades. Evolution and Development, 8:524-536. https://doi.org/10.1111/j.1525-142x.2006.00125.x

Schoch, R.R. and Sues, H-D. 2015. A Middle Triassic stem-turtle and the evolution of the turtle body plan. Nature, 523:584-587. https://doi.org/10.1038/nature14472

Schoch, R.R. and Sues, H-D. 2018. Osteology of the Middle Triassic stem-turtle Pappochelys rosinae and the early evolution of the turtle skeleton. Journal of Systematic Paleontology, 16:927-965. https://doi.org/10.1080/14772019.2017.1354936

Schoch, R.R., Klein, N., Scheyer, T.M. and Sues, H-D. 2019. Microanatomy of the stem-turtle Pappochelys rosinae indicates a predominantly fossorial mode of life and clarifies early steps in the evolution of the shell. Scientific Reports, 9:10430. https://doi.org/10.1038/s41598-019-46762-z

Smith, R., Rubidge, B., and Van der Walt, M. 2012. Therapsid biodiversity patterns and paleoenvironments of the Karoo Basin, South Africa. Forerunners of mammals: Radiation, Histology, Biology, 2012:223-246.

Spotila, J.R. and Tomillo, P.S. 2015. The Leatherback Turtle Biology and Conservation. John Hopkins University Press, Baltimore.

Stephens, P.R. and Wiens, J.J. 2003. Ecological diversification and phylogeny of emydid turtles. Biological Journal of the Linnean Society, 79:577-610. https://doi.org/10.1046/j.1095-8312.2003.00211.x

Storrs, G.W. 1991. Anatomy and relationships of Corosaurus alcovensis (Diapsida: Sauropterygia) and the Triassic Alcova Limestone of Wyoming. Peabody Museum of Natural History Bulletin, 44:1-163.

Stovall, J.W., Price, L.I., and Romer, A.S. 1966. The postcranial skeleton of the giant Permian pelycosaur Cotylorhynchus romeri. Bulletin of the Museum of Comparative Zoology, 135:130.

Sulej, T., Niedźwiedzki, G., and Bronowicz, R. 2012. A new Late Triassic vertebrate fauna from Poland with turtles, aetosaurs, and coelophysoid dinosaurs. Journal of Vertebrate Paleontology, 32:1033-1041. https://doi.org/10.1080/02724634.2012.694384

Szczygielski, T. 2017. Homeotic shift at the dawn of the turtle evolution. Royal Society Open Science, 4:4. https://doi.org/10.1098/rsos.160933

Szczygielski, T. and Sulej, T. 2016. Revision of the Triassic European turtles Proterochersis and Murrhardtia (Reptilia, Testudinata, Proterochersidae), with the description of new taxa from Poland and Germany. Zoological Journal of the Linnean Society, 177:395-427. https://doi.org/10.1111/zoj.12374

Szczygielski, T. and Sulej, T. 2019. The early composition and evolution of the turtle shell (Reptilia, Testudinata). Palaeontology, 62:375-415. https://doi.org/10.1111/pala.12403

Szczygielski T., Słowiak J., and Dróżdż D. 2018. Shell variability in the stem turtles Proterochersis spp. PeerJ, 6:e6134. https://doi.org/10.7717/peerj.6134

Tsuji, L.A. and Müller, J. 2009. Assembling the history of the Parareptilia: phylogeny, diversification, and a new definition of the clade. Fossil Record, 12:71-81. https://doi.org/10.1002/mmng.200800011

Van Den Brandt, M.J., Abdala, F., and Rubidge, B.S. 2019. Cranial morphology and phylogenetic relationships of the middle Permian pareiasaur Embrithosaurus schwarzi from the Karoo Basin of South Africa. Zoological Journal of the Linnean Society, 20:1-40. https://doi.org/10.1093/zoolinnean/zlz064

Watson, D.M.S. 1914. Eunotosaurus africanus Seeley, and the ancestry of the Chelonia. Proceedings of the Zoological Society of London, 11:1011-1020. https://doi.org/10.1111/j.1469-7998.1914.tb07724.x

Werneburg, I. and Sánchez-Villagra, M.R. 2009. Timing of organogenesis support basal position of turtles in the amniote tree of life. BMC Evolutionary Biology, 9:1-9. https://doi.org/10.1186/1471-2148-9-82 
LICHTIG \& LUCAS: TRIASSIC TURTLE CHINLECHELYS

Wing, S.L. and Sues, H.-D. 1992. Mesozoic and early Cenozoic terrestrial ecosystems, p. 327416. In Behrensmeyer, A.K., Damuth, J.D., DiMichele, W.A., Potts, R., Sues, H.D., and Wing, S.L. (eds.), Terrestrial Ecosystems Through Time. University of Chicago Press, Chicago.

Zug, G.R. 1971. Buoyancy, locomotion, morphology of the pelvic girdle and hindlimb, and systematics of cryptodiran turtles. Miscellaneous Publications of the Museum of Zoology, University of Michigan, 142:1-98. 


\title{
APPENDICES
}

All appendices are available in zipped files for download at https://palaeo-electronica.org/content/2021/3316-triassic-turtle-chinlechelys.

\begin{abstract}
APPENDIX 1
Coding issues in Lyson et al. (2013b) and Schoch and Sues (2015).
\end{abstract}

\section{APPENDIX 2}

Coding changes from Szczygielski (2017)

\section{APPENDIX 3}

Revised coding of the matrix of Szczygielski (2017) with Chinlechelys tenertesta and Anthodon spp. added and revised coding of Proganochelys quenstedti, Odontochelys, Pappochelys, Trilophosaurus and the Caseidae as well as with two new characters added.

\section{APPENDIX 4}

A revised list of characters and states as used in this paper. This is primarily based on Szczygielski (2017), additions are in bold.

\section{APPENDIX 5}

APPENDIX FIGURE 1. 3D Photogrammetric model of the first segment of the vertebral series of Chinlechelys tenertesta NMMNH P-16697-8.

APPENDIX FIGURE 2. 3D Photogrammetric model of the second segment of the vertebral series of Chinlechelys tenertesta NMMNH P-16697-19.

APPENDIX FIGURE 3. 3D Photogrammetric model of the third segment of the vertebral series of Chinlechelys tenertesta NMMNH P-16697-14.

APPENDIX FIGURE 4. 3D Photogrammetric model of the probable costal fragment of Chinlechelys tenertesta NMMNH P-16697-2.

APPENDIX FIGURE 5. 3D Photogrammetric model of the peripherals and supraperipherals of Chinlechelys tenertesta NMMNH P-16697-9.

APPENDIX FIGURE 6. 3D Photogrammetric model of the dorsal side of the skull fragment of Chinlechelys tenertesta NMMNH P-16697-12.

APPENDIX FIGURE 7. 3D Photogrammetric model of the ventral side of the skull fragment of Chinlechelys tenertesta NMMNH P-16697-12. 